\title{
La publicidad directa al público de los medicamentos con receta: el justo equilibrio entre los beneficios y los riesgos*
}

M. Asunción Torres López

DOI: https://doi.org/10.47623/ivap-rvap.109.2017.1.08

\begin{abstract}
Sumario: I. Aspectos generales del régimen jurídico de la publicidad de los medicamentos en España: 1. Marco jurídico. 2. El conflicto de derechos: los bienes jurídicos protegidos. 2.1. La libertad de expresión y el derecho a realizar publicidad comercial. 2.2. El derecho a la salud y su protección jurídica.-II. La publicidad de medicamentos directa al público: 1. Punto de partida y marco general. 2. Publicidad directa al público de los medicamentos cuyo uso no requiere receta médica. 3. Publicidad directa al público de los medicamentos cuyo uso requiera la previa prescripción médica (medicamentos con receta).-III. La publicidad directa al público de medicamentos con receta en Estados Unidos: 1. El debate sobre la permisión de la publicidad directa al público de medicamentos con receta. 2. Breve referencia a la competencia en materia de medicamentos y de publicidad en Estados Unidos: La Administración de Alimentos y Medicamentos (FDA) y la Comisión Federal de Comercio (FTC). - IV. Un apunte sobre la publicidad de los medicamentos en el entorno online. $-V$. Consideraciones finales: entre los riesgos y los beneficios de la publicidad directa al público de los medicamentos con receta, una posición favorable a la misma, pero condicionada al cumplimiento de requisitos legales.
\end{abstract}

\footnotetext{
* Trabajo realizado en el marco del Proyecto de Investigación I+D del Ministerio de Economía y Competitividad, Programa Estatal de Fomento de la Investigación Científica y Técnica de Excelencia, Subprograma de Generación del Conocimiento, DER2013-48665-P, sobre la Evaluación y Gestión de Riesgos en el campo de los Medicamentos y Alimentos: Farmacovigilancia y Seguridad Alimentaria (IP principal del Proyecto).
} 


\section{Aspectos generales del régimen jurídico de la publicidad de los medicamentos en España}

\section{Marco jurídico}

El sistema sanitario es un sistema público en el que el Estado se ha convertido en el garante del derecho a la salud del ciudadano. La consideración del acceso al sistema sanitario como una responsabilidad pública justifica la injerencia del Estado en derechos constitucionales como es el derecho a la libertad de expresión o la libertad de empresa y en la posibilidad de que las empresas farmacéuticas realicen publicidad directa al público de sus productos, siempre que se trate de medicamentos que necesiten receta médica. Si bien, aún en el caso de una publicidad de medicamentos que no necesiten receta, como veremos, se considera que la publicidad es concebida legalmente en su vertiente de información, dejando en un plano secundario el componente esencial de la persuasión, que persigue el fin último de vender el producto; ello se debe a que las exigencias legales en cuanto a los contenidos y la forma de exponer la publicidad van enfocadas exclusivamente a la finalidad de educar al público en el cuidado de su salud.

En España, el marco jurídico general de la publicidad viene determinado por la Ley 34/1988, de 15 de noviembre, General de Publicidad (LGP), norma de cabecera que establece el régimen general de la publicidad, aunque también tiene aplicación la Ley 31/1991, de 10 de mayo, de Competencia Desleal (LCD)(1). La LGP define la publicidad como "toda forma de comunicación realizada por una persona física o jurídica, pública o privada, en el ejercicio de una actividad comercial, industrial, artesanal o profesional, con el fin de promover de forma directa o indirecta la contratación de bienes muebles o inmuebles, servicios, derechos y obligaciones". Esta definición, excluye del ámbito de aplicación de la norma otro tipo de publicidad en la que puede no concurrir una finalidad comercial. Ello hace que nos encontremos con otras normas que deben ser tenidas en cuenta a la hora de determinar el completo marco jurídico de la publicidad que en este estudio viene referida a los medicamentos $y$, más en concreto, la publicidad de los medicamentos con receta directa al público.

Además, según cuál sea el soporte utilizado en la publicidad, existe una regulación específica. Así, cuando la publicidad utiliza un formato audiovisual, la Ley 7/2010, de 31 de marzo, General de Comunicación Audio-

(1) Ambas normas modificadas por la Ley 29/2009, de 30 de diciembre, que modifica el régimen legal de la competencia desleal y de la publicidad para la mejora de la protección de los consumidores y usuarios. 
visual (LGCA) establece reglas aplicadas al medio. Cuando el soporte de la publicidad es Internet, donde los formatos son múltiples, hemos de considerar que las reglas generales de publicidad son las mismas; si bien, no existe un marco jurídico global que regule la Red, toda vez que Internet no conoce de fronteras entre Estados, por lo que la dificultad de determinar la normativa aplicable en un caso concreto es evidente, dado el principio de territorialidad de las normas. En este sentido, hemos de tener en cuenta la Ley 34/2002, de 11 de julio, de los Servicios de la Información y del Comercio Electrónico (LSSI).

Cuando el producto objeto de la actividad publicitaria es un medicamento, además del marco jurídico general de la publicidad, y por expresa remisión de la misma a una regulación específica, la primera norma que regula la publicidad es el Real Decreto 1416/1994, de 25 de junio, por el que se regula la publicidad de los medicamentos de uso humano, en ejecución de las disposiciones de la Directiva 92/98/CEE, del Consejo, sobre esta materia y bajo la cobertura legal de la Ley 25/1990, de 20 de diciembre, del Medicamento. Las modificaciones posteriores de que ha sido objeto esta norma se deben, de una parte, a la derogación de la Directiva de 1992, por la actualmente vigente, la Directiva 2001/83/CE, del Consejo y el Parlamento Europeo, de 6 de noviembre de 2001, que establece un código comunitario sobre medicamentos de uso humano (2); y, de otra parte, a las modificaciones de la Ley del Medicamento, fruto de las cuales se dicta el Real Decreto Legislativo 1/2015, de 24 de julio, por el que se aprueba el Texto Refundido de la Ley de Garantías y Uso Racional de los Medicamentos y Productos Sanitarios. Estas dos normas conforman el marco jurídico específico en nuestro Estado derivado de la normativa de la Unión Europea en materia de la publicidad de medicamentos.

La Directiva se aplica a los medicamentos de uso humano producidos industrialmente y destinados a ser comercializados en los Estados miembros e impone al respecto una serie de prohibiciones en la actividad publicitaria que los Estados miembros han de respetar. Expresamente exige que los Estados miembros establezcan en sus ordenamientos internos, esencialmente, dos prohibiciones:

(2) La Directiva de 2001 viene a sustituir a la Directiva 1992/28/CEE, de 31 de marzo, primera Directiva que se dicta sobre la publicidad de medicamentos de uso humano. La Directiva de 2001 continúa vigente, si bien, ha sido objeto de modificaciones posteriores, como la llevada a cabo por la Directiva 2012/26/UE, de 25 de octubre, en lo referente a la farmacovigilancia; la Directiva 2011/62/UE, de 8 de junio, en lo relativo a la prevención de la entrada de medicamentos falsificados en la cadena de suministro legal; o también, en la Directiva 2010/84/UE, de 15 de diciembre, etc. Sin embargo, en lo que respecta a la regulación de la publicidad directa al público de medicamentos no ha sufrido modificaciones relevantes. 
1) De un lado, se prohíbe toda publicidad de un medicamento para el que no se haya otorgado una autorización de comercialización conforme al Derecho comunitario.

2) De otro lado, se prohíbe la publicidad directa al público de los medicamentos con receta.

El régimen jurídico específico, al que nos referimos más adelante, es resultado de un previo juicio de valor entre dos bienes jurídicos enfrentados, de un lado, el derecho a la salud y, de otro lado, el derecho a la actividad publicitaria, amparada, conforme a lo establecido por nuestro Tribunal Supremo, por la libertad de expresión. El resultado de ese juicio de valor justifica los límites a la libertad de expresión a favor del necesario uso racional de los medicamentos, como marca la Directiva.

La regulación concreta nos lleva necesariamente a plantear una clara definición de derechos: el derecho de protección de la salud, derivado del artículo $43 \mathrm{CE}$; la libertad de expresión y el derecho a la información (en su vertiente activa y pasiva) del artículo $20 \mathrm{CE}$; y también la libertad de empresa, reconocida en el artículo $38 \mathrm{CE}$. Ello nos permitirá realizar un adecuado análisis de algunas cuestiones esenciales de la regulación que en este momento tan solo advertimos:

a) En primer lugar, tan solo está permitida la publicidad de medicamentos que no requieran de prescripción médica, en otro caso está prohibida. La primera cuestión a debatir es si tal prohibición está justificada. Ello implica que consideremos los bienes jurídicos que entran en conflicto, cuáles son los derechos enfrentados y qué protección merecen. El derecho a la salud y el derecho a la actividad publicitaria. Esto nos lleva a la segunda precisión.

b) Si la publicidad es o no un derecho fundamental. Aunque a partir de la Sentencia del Tribunal Supremo de 2010, se considera que la publicidad está amparada por el derecho fundamental a la libertad de expresión del artículo $20 \mathrm{CE}$, debe ser analizado también desde la perspectiva del derecho a la libertad de empresa.

c) En tercer lugar, las exigencias establecidas por la legislación para realizar la publicidad de medicamentos (cuando no requieren una prescripción médica), desembocan en la categorización de un tipo de publicidad-información, relajando, en gran medida, el elemento esencial de la publicidad que es, junto a la información, la persuasión. En este sentido, la actividad publicitaria se convierte en una acción de informar sobre las características del producto al consumidor, actividad que, en principio, no corresponde realizar a la empresa cuando lo que pretende, en todo caso, es vender un producto. De ahí la importancia que adquiere la función de la Administración Pública en cuanto fuente de información al consumidor. 
d) En cuarto lugar, debe hacerse una consideración al desarrollo de la sociedad digital que ha llevado a que la actividad publicitaria se desarrolle a través de múltiples formatos y medios, sobre los que el alcance de la legislación está condicionado por el principio de territorialidad de las normas, lo que se opone frontalmente al carácter abierto de la Red. Ello exige un replanteamiento de la regulación, nuevas técnicas de articulación del derecho a la información y el fomento de la autorregulación.

\section{El conflicto de derechos: los bienes jurídicos protegidos}

El fin esencial de la normativa es garantizar un uso racional de los medicamentos, que sea seguro y eficaz para los pacientes y potenciales pacientes. Por ello, el legislador europeo y los legisladores de los Estados miembros, han considerado necesario regular, de modo específico, la publicidad de los medicamentos, en tanto en cuanto, un uso indebido de la publicidad puede dar lugar a un uso irracional de los mismos, que, a su vez, puede derivar en un daño a la salud. Se ponen, pues, en conflicto dos bienes jurídicos dignos de protección constitucional, y según dónde situemos el peso de la balanza, según cómo articulemos el camino jurídico para alcanzar el fin, prevalecerá uno u otro. Así, de un lado, el derecho a realizar publicidad, de otro lado, el derecho a la salud. Este conflicto de derechos nos lleva a plantear una serie de cuestiones previas al análisis de la normativa y sobre la base de las cuales se asentará nuestra conclusión. Así, debemos establecer cuál es el nivel de protección que merecen ambos derechos y hasta dónde alcanza la responsabilidad de los poderes públicos en la consecución de ambos derechos.

La literatura jurídica sobre ambos derechos es importante, por lo que, sobre la base de la misma, nos limitaremos a acentuar los aspectos de mayor interés a este trabajo (3).

(3) Con carácter específico en materia de medicamentos, véase J. CAYÓN DE LAS CUEVAS (2013), «El tratamiento jurídico de la Publicidad de Medicamentos de uso humano: entre la libertad de empresa y la protección de la salud: tratamiento jurídico", en A. PALOMAR OLMEDA y J. CANTERO MARTíNEZ (dir.), Tratado de Derecho Sanitario, Pamplona: Aranzadi; N. IRACULIS ARREGUI (2008), La publicidad de medicamentos, Ed. La Ley; T. DE LA CUADRA SALCEDO (1999), "La regulación de la publicidad de los medicamentos de uso humano", en VV.AA., Derecho de la sanidad y los medicamentos: seis estudios, Madrid: Ministerio de Sanidad y Consumo. Universidad Carlos III.

Con carácter general, véase A. RUBÍ PUIG (2005), "Publicidad y libertad de expresión", Revista para el análisis del Derecho, 311, sobre el la publicidad como libertad de expresión y la doctrina jurisprudencial estadounidense en materia de protección constitucional de la publicidad. $\mathrm{S}$. SOLANS BALLARINI (2010), "Publicidad y libertad de expresión: comentario a la Sentencia del Tribunal Supremo, Sala de lo Civil, pleno de 15 de enero de 2010", Noticias Jurídicas, diciembre de 2010. 


\subsection{LA LIBERTAD DE EXPRESIÓN Y EL DERECHO A REALIZAR PUBLICIDAD COMERCIAL}

La libertad de expresión es un derecho fundamental recogido en el artículo 20 de la Constitución Española, en el que se reconoce y protege el derecho "a expresar y difundir libremente los pensamientos, ideas y opiniones mediante la palabra, el escrito, o cualquier otro medio de reproducción», así como también el derecho "a comunicar y recibir libremente información veraz por cualquier medio de difusión". Se diferencia, en realidad, dos derechos distintos aunque muy relacionados, de un lado, la libertad de expresión y, de otro lado, el derecho a recibir y comunicar información.

La libertad de expresión goza en la mayoría de los Estados democráticos del máximo nivel de protección jurídica, al ser considerado un fundamento esencial de la sociedad, que contribuye, además, a formar una opinión pública libre. Si bien, no es un derecho ilimitado, lo que permite la intervención del mismo en aras a proteger otros bienes jurídicos con los que entre en conflicto (seguridad, orden público, ...); la libertad de expresión está sometida a los límites establecidos por cualquiera de las Leyes sobre las que pueda tener incidencia (4).

En España, el derecho a realizar publicidad comercial se considera dentro de este derecho fundamental a partir del año 2010, con la Sentencia delTribunal Supremo de 15 de enero de 2010, en el caso Mitsubishi (5), recogiendo tanto la doctrina del Tribunal Europeo de Derechos humanos como delTribunal de Justicia de la Unión Europea (6). Hasta entonces gozaba de la protección de la libertad de empresa, recogida en el artículo $38 \mathrm{CE}$, dentro del grupo de derechos y deberes del ciudadano, pero

(4) Así, en la Sentencia delTSJ de Madrid (Sala de lo Contencioso-Administrativo), de 15 de junio de 2004, (RJCA 2005\365) se afirma en su fundamento jurídico cuarto. De la que se deriva, además, que es irrelevante que se considere o no la actividad publicitaria como libertad de expresión, pues lo esencial es el objeto de la actividad publicitaria, un medicamento, y la aplicación de la normativa específica en materia de publicidad de medicamentos. El objeto del caso se centra en la ilicitud de un publirreportaje financiado por un laboratorio con el fin de incitar y promover la prescripción de determinados medicamentos en detrimento de otros; se pone en entredicho la eficacia y seguridad de los medicamentos antidepresivos genéricos, frente al original comercializado por el laboratorio. El reportaje resulta ser «tendencioso e infundadamente alarmista sobre los medicamentos genéricos».

(5) STS, Sala de lo Civil, de 15 de enero de 2010 (RJ\2010\415)

(6) Ámbito tratado ampliamente por la doctrina; solo basta recordar el contenido del artículo 10 del Convenio Europeo de Derechos Humanos, que reconoce el derecho de toda persona a la libertad de expresión; libertad que comprende la libertad de opinión y la libertad de recibir o de comunicar informaciones o ideas sin que pueda haber injerencias de autoridades públicas y sin consideración de fronteras. Si bien, ello no impide que los Estados sometan las empresas de radiodifusión, de cinematografía o de televisión a un régimen de autorización previa. Por otra parte, el ejercicio de estas libertades, que entrañan deberes y responsabilidades, puede ser sometido a ciertas formalidades, condiciones, restricciones o sanciones previstas por la ley, que constituyan medidas necesarias, en su sociedad democrática, para la seguridad nacional, la integridad territorial o la seguridad pública, la defensa del orden y la prevención del delito, la protección de la salud o de la moral, la protección 
no como derecho fundamental, que permite defender este derecho a través del recurso de amparo ante el Tribunal Constitucional. De lo que se trata es de determinar si el fin comercial de la publicidad y su objetivo principal de obtener un beneficio de carácter económico, es o no relevante para incluir este derecho en la libertad de expresión de ideas, pensamientos $u$ opiniones o en el derecho a comunicar información veraz por cualquier medio de difusión.

Hasta el caso Mitsubishi los Tribunales españoles han considerado fuera de este derecho fundamental la publicidad, precisamente por el fin comercial que la caracteriza y el ánimo de disuadir al público, más que el de expresar una idea u opinión, o el de dar una determinada información que, en todo caso, ha de ser veraz(7). En esta Sentencia el Tribunal Supremo reconoce que la publicidad es una manifestación de la libertad de expresión y de información reconocida en el artículo $20 \mathrm{CE}$ y, aplicando la doctrina delTEDH, cualquier restricción a la publicidad comercial debe estar justificada por un interés público y ser razonablemente proporcionada. El Tribunal Supremo afirma que la publicidad es una forma de comunicación «con fines de promoción de la celebración de contratos sobre bienes

de la reputación o de los derechos ajenos, para impedir la divulgación de informaciones confidenciales o para la garantizar la autoridad y la imparcialidad del poder judicial.

Pues bien, la interpretación de este artículo ha llevado al Tribunal Europeo de Derechos Humanos (TEDH) a considerar que los poderes públicos de los Estados no pueden intervenir la esfera de autonomía que el Convenio confiere a los derechos, si bien es posible establecer límites para lo cual impone unas condiciones que, básicamente, se concretan en las siguientes: 1.-Que los límites estén previstos en la Ley. 2. - Que sean necesarios en una sociedad democrática para conseguir un fin legítimo. 3.-Que sean proporcionales con relación al fin legítimo perseguido.

En este sentido y, entre otros estudios, puede verse T. FREIXET SANJUÁN (2003), "EITribunal Europeo de Derechos Humanos y las libertades de la comunicación", Revista de Derecho Comunitario Europeo, 15, págs. 463-497, en el que realiza un análisis de la doctrina delTEDH sobre la importancia de los derechos y sus límites, en concreto de la libertad de expresión; en este sentido, el TEDH elabora un test para aplicarlo siempre que detecte injerencias de las autoridades en los derechos amparados por el Convenio y, como hemos visto, "la limitación o injerencia ha de estar prevista en una Ley, ha de estar justificada en una finalidad legítima, ha de ser necesaria en una sociedad democrática y debe ser proporcionada a la finalidad legítima perseguida».

Por otra parte, este test de los límites delTEDH es de especial interés en un Estado como el nuestro en el que no existe una regulación concreta sobre el alcance que puedan tener las limitaciones que se puedan imponer a los Estados. De modo que los límites que se pueden imponer a los derechos, o bien son límites específicos directamente establecidos en la Constitución para un derecho en concreto, o bien hay que deducirlos del propio sistema de derechos y con relación al marco general constitucional, esto es, inferirlo de la propia Constitución a través del conflicto de derechos o de la interpretación que de los derechos pueda hacerse a partir del artículo $10.2 \mathrm{CE}$.

Así, STEDH de 24 de febrero de 1994, asunto Casado Coca y STEDH de 17 de octubre de 2002, asunto Stambuk, entre otras.

(7) En la Sentencia de la Audiencia Provincial de Madrid, de 28 julio (JUR\2007\167560), se alude que los derechos que normalmente se invocan en el campo de la actividad publicitaria son la libertad de expresión e información y la libertad de iniciativa económica y de empresa. Y recuerda que en Europa a diferencia de EE.UU. y Canadá, la jurisprudencia viene rechazando que sea la libertad de expresión y de información el basamento de la publicidad. La publicidad ha tenido como fundamento la libertad de empresa y la propiedad privada. 
y servicios" y que esa comunicación "puede tener un contenido informativo o integrado por ideas u opiniones o ambos a la vez" y "con una relevancia cada vez mayor en el proceso de toma de decisiones en el mercado por parte de quienes son sus destinatarios"; además, expresa con claridad que aunque la publicidad sea una manifestación del ejercicio de la libertad de empresa, ello no justifica que se excluya del alcance de la libertad de expresión del artículo 20 CE (8).

El objeto de la libertad de expresión es la manifestación de pensamientos, ideas y opiniones, es la manifestación de creencias, de juicios de valor; por lo que cabe preguntarse si la actividad publicitaria, si el derecho a realizar comunicaciones comerciales queda amparado por la libertad de expresión, toda vez que la publicidad tienen como rasgo definitorio e imprescindible la intención de persuadir a su destinatario a que consuma el producto que se publicita, más allá de su contenido informativo, que debe ser veraz.

En mi opinión, el ánimo de lucro que encierra la publicidad la excluye del concepto de libertad de expresión, por lo que no comparto la afirmación contenida en esta Sentencia; las comunicaciones comerciales constituyen una actividad amparada por la libertad de empresa, más que por la libertad de expresión. El factor económico, al que alude la Sentencia como "voto económico" emitido en el mercado por el destinatario de la publicidad, es clave para definir los límites de lo que no debe considerarse libertad de expresión (9).

Pero, más allá de la ubicación constitucional de la publicidad, comparto las conclusiones a las que llega el Tribunal en cuanto al reconocimiento de la protección del derecho a realizar publicidad, sin tener que identificar ésta con la libertad de expresión.

En este sentido, debemos tener en cuenta que la libertad de empresa es considerada un derecho fundamental $y$, como tal, debe ser sometida a la teoría de los límites de los derechos constitucionales, en la que lo que se pretende es lograr el justo equilibrio entre los riesgos y beneficios de los derechos en conflicto, pero sin anular uno de ellos. Como también comparto, la consideración como derecho fundamental de un principio rector de la política social y económica como es el derecho a la salud.

(8) Fundamento Jurídico Quinto.

(9) En concreto señala que no puede discriminarse en función de cuál sea la materia objeto de la comunicación, pues ello generaría inseguridad al tener que identificar múltiples categorías intermedias en la que llama una "realidad multiforme». Además, muchos mensajes comerciales "contribuyen a que el destinatario emita su voto económico en el mercado estando mejor informado, a causa del significado que tiene la mera participación del anunciante en la costosa actividad publicitaria....". Al margen de que tal circunstancia pudiera darse en algún caso, sí es cierto que el interés económico de la industria farmacéutica, no es otro más que el de vender el producto, aunque las restricciones legales obligan al preponderante carácter informativo de la publicidad de los medicamentos. 


\subsection{EL DERECHO A LA SALUD Y SU PROTECCIÓN JURÍDICA}

La regulación de la publicidad del medicamento gira en torno a la protección de otro derecho constitucional, cual es el derecho a la salud, que se ha derivado del artículo $43 \mathrm{CE}$, ubicado entre los llamados «principios rectores de la política social y económica", con un nivel de protección constitucional, en principio, inferior al conferido a los derechos fundamentales, entre los que se encuentra la libertad de expresión, e inferior también, al reconocido a los derechos y deberes de los ciudadanos, entre los que se encuentra la libertad de empresa. En concreto, el artículo 43 reconoce en su primer apartado el derecho a la protección de la salud y en su segundo apartado encomienda a los poderes públicos la función de organizar y tutelar la salud pública a través de medidas preventivas y de las prestaciones y servicios que sea necesarios, derivando la regulación de los derechos y deberes de todos los implicados a la Ley.

El derecho a la salud se contempla como un derecho prestacional y de configuración legal. El Estado es prestador del servicio y garante del mismo. A él corresponde la responsabilidad por los daños causados a los pacientes derivados del funcionamiento del servicio público sanitario, siempre y cuando se pruebe la adecuada relación de causalidad entre el funcionamiento del servicio público y el daño, y se pruebe, asimismo, la vulneración de la "Lex artis» en el caso concreto, conforme al instituto legal de la responsabilidad patrimonial de la Administración Pública.

Se da cumplimiento a este mandato constitucional a través, en primer lugar, de la Ley 14/1986, de 25 de abril, General de Sanidad. Más tarde se completa y desarrolla a través de la Ley $41 / 2002$, de 14 de noviembre, de Autonomía del Paciente; La Ley 16/2003, de 28 de mayo, de Cohesión y Calidad del Sistema Nacional de Salud. A partir de ahí se diseña un sistema de garantías en el ámbito de la salud y de reconocimiento de derechos sanitarios de gran importancia y que conforma una nueva relación médico-paciente (10). Siendo un derecho de carácter prestacional, conformado por un marco legal específico que permite al ciudadano exigir de los poderes públicos un nivel mínimo de prestaciones; hasta dónde llegue ese nivel mínimo depende del Estado.

(10) Véase J. CANTERO MARTÍNEZ (2013), "Constitución y derecho a la protección de la salud. ¿Existe algún límite frente a los recortes sanitarios?", Revista CESCO de Derecho de Consumo,8, págs.. 7 y ss. J.M. FERNÁNDEZ PASTRANA (1984), El servicio público de la sanidad: el marco constitucional, Madrid: Civitas, págs. 55 y ss.; E. COBREROS MENDAZONA (1988), Los tratamientos sanitarios obligatorios y el derecho a la salud (Estudio sistemático de los ordenamientos italiano y español), Instituto Vasco de Administración Pública. Para una aproximación multinivel y de Derecho comparado al estudio del derecho a la protección de la salud, analizando los instrumentos al respecto en el orden internacional, constitucional comparado, europeo, español y autonómico, véase F.M. BOMBILLAR SÁENZ y A. PÉREZ MIRAS (2015), "El derecho a la protección de la salud desde una perspectiva multinivel y de derecho comparado", Revista Europea de Derechos Fundamentales, 25, págs. 299-331. 
La sanidad se ha configurado como un servicio público, de prestación pública o privada. Y ello implica responsabilidad pública $\mathrm{y}$, por tanto, la necesidad de establecer una regulación adecuada del sistema, lo que conlleva una intervención administrativa, del tipo que sea, pero intervención, a los efectos de dar plena efectividad al derecho de protección de la salud contemplado en la Constitución. $Y$ aunque este derecho sea un "principio rector de la política social y económica», la regulación legal del mismo ha llevado a su consideración de derecho fundamental en un plano material.

Uno de los ámbitos de intervención administrativa lo constituye el sector de los medicamentos y, dentro de éste, descansando en esta base jurídica y planteamiento cuyo fin último es el uso racional de los medicamentos, más en concreto, es objeto de intervención administrativa la publicidad de los medicamentos. El Estado interviene una libertad fundamental, la libertad de expresión (conforme a la doctrina delTS), o libertad de empresa, justificada en la garantía de un «principio rector de la política social y económica», la protección del derecho a la salud, considerado derecho fundamental, con el fin de garantizar el uso racional y eficaz de los medicamentos por los pacientes o potenciales pacientes, toda vez que una actividad publicitaria del medicamento podría afectar negativamente a este fin esencial del Estado si no cumple con determinadas condiciones, y no solo, con la normativa general en materia de publicidad, que establece los supuestos de publicidad ilícita y los mecanismos de reacción jurídica que frente a la misma proceden. Como veremos, el régimen jurídico de la publicidad directa al público de los medicamentos, establece límites a la actividad publicitaria cuando se trata de medicamentos cuyo uso no requiere de una prescripción médica; y establece una prohibición absoluta de la actividad cuando se trate de medicamentos cuyo uso requiera un prescripción médica.

A continuación realizamos un análisis de este régimen jurídico al que haremos algunas consideraciones.

\section{La publicidad de medicamentos directa al público}

\section{Punto de partida y marco general}

La Ley General de Publicidad, como hemos indicado, establece una serie de productos o servicios cuya publicidad puede ser objeto de un tratamiento jurídico específico, entre los que se encuentran los materiales o productos sanitarios, así como los bienes o servicios susceptibles de generar riesgos para la salud o seguridad de las personas. Prescribiendo, además, que dicha regulación específica debe precisar la naturaleza y ca- 
racterísticas de los productos, bienes, actividades y servicios; debe recoger los riesgos derivados de la utilización racional de los mismos; la forma y las condiciones de difusión de los mensajes publicitarios; los requisitos y el régimen al que debe someterse la autorización administrativa previa a la difusión de la publicidad cuando esta sea obligatoria; así como, la audiencia en la elaboración de los reglamentos de las organizaciones empresariales y de las asociaciones de agencias, de anunciantes y de consumidores y usuarios, a través de sus órganos de representación institucional (11).

En concreto, el artículo 5.4 LGP se remite al régimen jurídico específico de la publicidad de los medicamentos, constituido por el Real Decreto Legislativo 1/2015, de 24 de julio, por el que se aprueba el texto refundido de la Ley de garantías y uso racional de los medicamentos y productos sanitarios, estando vigente con carácter específico el Real Decreto 1416/1994, de 25 de junio, por el que se regula la publicidad de los medicamentos de uso humano.

La Ley del Uso Racional del Medicamento, establece unas garantías de información que se deben proporcionar tanto a los profesionales como al público y entre estas garantías, se incluye la publicidad. En el marco de esta legislación, se define la publicidad como «toda forma de oferta informativa, de prospección o de incitación destinada a promover la prescripción, la dispensación, la venta o el consumo de medicamentos". Concepto que se identifica por dos elementos, de un lado, la información (que ha de ser veraz) y, de otro lado, elemento esencial de la publicidad y fin último de la misma, la persuasión.

No olvidemos que la publicidad es un medio que tienen las empresas con el objetivo preferente de captar la atención del público para conseguir mayores ventas de sus productos. Las empresas farmacéuticas a través de la publicidad informan de la existencia de sus productos al público y a los profesionales de la salud. Es un sector en el que la actividad publicitaria es extraordinaria y, en muchas ocasiones, decisiva, no ya para informar, sino para vender, perspectiva que hemos de tener muy presente.

La Ley distingue dos regímenes jurídicos según a quién vaya destinada la publicidad:

1) La publicidad de medicamentos destinada al público.

2) La publicidad destinada a profesionales o personas facultadas para prescribirlos.

(11) M.J. ROZADOS OLIVA (2014), «Derecho de la publicidad (I): aspectos generales, Régimen jurídico de la publicidad según la finalidad", en M.A. TORRES LÓPEZ, J.M. SOUVIRÓN MORENILLA y M.J. ROZADOS OLIVA, Elementos para el estudio del Derecho de la Comunicación, Madrid: Tecnos; del mismo autor, El Derecho Administrativo de la Publicidad (2009), Valencia:Tirant Lo Blanch. 
El objeto de nuestro estudio es el primero de ellos, esto es, la publicidad de medicamentos destinada al público $y$, en concreto, la referida a los medicamentos sujetos a prescripción médica(12).

En todo caso, la publicidad de un medicamento debe cumplir las siguientes tres obligaciones:

a) El medicamento ha de contar con la oportuna autorización administrativa. Sin la autorización administrativa, control previo a la actividad, no es posible realizar publicidad alguna de un medicamento.

b) El contenido de la publicidad debe ajustarse a las informaciones que figuran en la ficha técnica.

c) El contenido de la publicidad debe favorecer la utilización racional del medicamento, a través de la presentación del mismo de forma objetiva y sin exagerar sus propiedades.

Estas tres obligaciones condicionan de manera importante el ejercicio del derecho a la libertad de expresión e información que da cobijo a la actividad publicitaria con fines comerciales. En este sentido, aplicando el test de condicionalidad del Tribunal Europeo de Derechos Humanos, observamos que los límites exigidos están previstos en una Ley; que el equilibrio entre límites y el fin legítimo perseguido puede entrar dentro de lo razonable; $y$, por último, que la necesidad de establecer tales límites en una sociedad democrática para conseguir el fin perseguido también puede encontrar su justificación. Pero, del mismo modo que puede encontrar justificación, también podría defenderse lo contrario.

Ello exige un análisis normativo que pasa por responder a las siguientes cuestiones:

a) Cuáles son los límites a la publicidad directa al público de los medicamentos, lo que nos lleva a establecer la distinción entre la publicidad de los medicamentos sin receta y la de los medicamentos con receta.

b) Si estos límites son razonables.

c) Y, si son necesarios para lograr el uso racional de los medicamentos o, dicho de otro modo, para evitar un uso irracional e ineficaz de los medicamentos, (toda vez, que se trata de productos, bienes o servicios con cierto potencial de peligrosidad, especialmente cuando se trata de medicamentos para cuyo uso se exige una prescripción médica).

(12) Sobre la publicidad destinada a profesionales puede verse el estudio de N. IRÁCULIS ARREGUI (2011), «El derecho de la Unión Europea y la publicidad de medicamentos destinada a profesionales: estudio jurisprudencial del principio de adecuación a la ficha técnica», Revista Española de Derecho Europeo, 40. Así también, J. CAYÓN DE LAS CUEVAS (2013), op. cit.

Es interesante también, L. GONZÁLEZ VAQUÉ (2008), "La sentencia "Ludwigs-Apotheke" relativa a la publicidad de los medicamentos: ¿Dónde estás "Keck y Mithouard"?", Revista Española de Derecho Europeo, 25. 
Las empresas farmacéuticas y los responsables de la publicidad de los productos y servicios sanitarios, encuentran una primera restricción a su derecho a realizar publicidad (libertad de expresión/libertad de empresa), que se ve negada con carácter absoluto en los casos en los que el uso del producto sanitario dependa de la oportuna receta. Junto a ello, está prohibida la publicidad de los medicamentos financiados con fondos públicos y la de aquellos productos que constituyan sustancias psicotrópicas o estupefacientes con arreglo a lo definido en los convenios internacionales. En los demás casos, esta libertad está condicionada a una serie de límites impuestos por los poderes públicos con el objeto de garantizar el uso racional de los medicamentos.

\section{Publicidad directa al público de los medicamentos cuyo uso no requiere receta médica}

El mensaje publicitario de un medicamento dirigido al público tiene fines promocionales $y$, esencialmente, de información. Si se trata de la primera vez que se publicita un medicamento, la Ley exige, en cuanto al contenido del mensaje publicitario que incluya:

a) La denominación del medicamento (13).

b) Las informaciones indispensables para promover su uso racional.

c) Una invitación expresa y visible a leer detenidamente las instrucciones del prospecto, embalaje exterior, etc.

d) Debe aparecer la mención «en caso de duda consulte a su farmacéutico" o expresión similar.

e) Debe ser evidente el carácter publicitario del mensaje y que quede especificado que el producto es un medicamento.

f) No deben incluirse expresiones que proporcionen seguridad de curación, ni testimonios sobre las virtudes del producto ni de profesionales o personas cuya notoriedad pueda inducir al consumo.

g) No puede utilizarse como argumento publicitario el hecho de haber obtenido autorización sanitaria en cualquier país o cualquier otra autorización.

Cuando el objetivo del mensaje publicitario es recordatorio de la denominación del medicamento, su contenido puede incluir únicamente la denominación del medicamentos, siempre que el medicamento sea suficientemente conocido por el público y haya permanecido en campañas promocionales al menos durante dos años.

(13) La Denominación Oficial Española o la Denominación Común Internacional, en su defecto, o la denominación usual científica cuando el medicamento contenga un único principio activo. 
Cuando el soporte de la publicidad es un medio audiovisual, la Ley específica tan solo exige que el mensaje publicitario cumpla con las condiciones de accesibilidad para personas con discapacidad. Si bien, cuando se trata de un medio audiovisual, se ha de estar a lo dispuesto en la Ley General de Comunicación Audiovisual, que establece unos tiempos y unos formatos específicos de la publicidad y, en ocasiones, puede ser difícil cumplir con las condiciones impuestas a la publicidad de los medicamentos. En concreto, esta Ley establece en su artículo 18.3 que está prohibida la comunicación comercial de medicamentos y productos sanitarios que contravenga la normativa específica en materia de publicidad de medicamentos y productos sanitarios. Especial atención requiere cuando el soporte utilizado es Internet.

Con el cumplimiento de estas condiciones la empresa puede publicitar el medicamento, una actividad que no requiere de autorización administrativa previa, pero que, sin embargo, sí está sometida a controles por parte de las Administraciones sanitarias con el fin de garantizar que los contenidos publicitarios son acordes a lo exigido por las normas de aplicación y a lo establecido en la autorización de comercialización del medicamento. La Ley permite que las Administraciones Sanitarias puedan imponer límites y condiciones a la publicidad cuando éstos se justifiquen en razones de salud pública o de seguridad de las personas.

Si bien, hemos de interpretar esta posibilidad con carácter excepcional o restrictivo, de modo que, solo en los casos en los que el peligro sea evidente deben establecerse tales límites, pero no cuando se trate de una mera "expectativa de peligro" o peligro potencial, pero no evidente. En estos casos, la actuación de la Administración se convierte en una decisión que podría vulnerar el derecho fundamental a la libertad de expresión o también a la libertad de empresa.

Además de determinarse legalmente cuál ha de ser el contenido mínimo del mensaje publicitario, la Ley establece prohibiciones específicas al contenido, enfocadas especialmente a salvaguardar la consulta médica o intervención quirúrgica, y no hacer diagnósticos o aconsejar un tratamiento por correspondencia; o a no sugerir que el efecto del medicamento está asegurado o que carece de efectos secundarios; si bien, en estos casos, la publicidad sería ilícita por no cumplir con el requisito general de la veracidad. Muchas de estas prohibiciones entran dentro del concepto de publicidad engañosa o publicidad falsa referido en la normativa general de publicidad.

Podemos sistematizar tales prohibiciones de la siguiente manera:

a) supuestos claros de publicidad ilícita por engañosa o falsa, porque no cumple con el requisito de la veracidad: 
- Sugerir que el efecto del medicamento está asegurado o que carece de efectos secundarios. En este caso, no se cumple con el contenido mínimo exigido en el mensaje publicitario y la publicidad es engañosa o falsa, toda vez que todos los medicamentos pueden tener efectos secundarios que, en ocasiones, dependen de el estado del paciente.

- Poder inducir, mediante una descripción o representación detallada de la anamnesis, a un falso autodiagnóstico.

- Referirse de forma abusiva, alarmante o engañosa a testimonios de curación (14).

- Utilizar de forma abusiva, alarmante o engañosa, representaciones visuales de las alteraciones del cuerpo humano producidas por enfermedades o lesiones, o de la acción de un medicamento en el cuerpo humano o en partes del mismo.

- Mencionar que el medicamento ha recibido la autorización sanitaria o cualquier otra autorización. Es una publicidad que induce a error, pues la comercialización de todo medicamento requiere de una autorización administrativa, en todo caso.

b) Prohibiciones que por sí mismas podrían no ser constitutivas de publicidad ilícita, pero, no obstante, son límites impuestos a la libertad de expresión/libertad de empresa que se legitiman por la prevalencia sobre la misma del derecho a la salud:

- Sugerir que su uso potencia el rendimiento deportivo.

- Referirse a una recomendación que hayan formulado científicos, profesionales de la salud $u$ otras personas que puedan, debido a su notoriedad, incitar al consumo de medicamentos.

- Sugerir que la seguridad o la eficacia del medicamento se debe a que se trata de una sustancia natural.

(14) Sobre el concepto de "testimonios de curación» a que alude la Directiva 2001/83/CE, se ha pronunciado el TJUE en la sentencia de 8 de noviembre de 2007, Caso Gintec International ImportExport GmbH contra Verband Sozialer Wettbewerb eV. Se le plantean varias cuestiones prejudiciales, siendo una de ellas que se aclare cuál es el significado en la Directiva de "testimonios de curación" y si la publicidad del medicamento contiene una valoración global positiva del mismo, sin mencionar una indicación terapéutica determinada, ello supone una referencia abusiva o engañosa. EITJUE, tras el análisis, concluye que la Directiva impone a los Estados miembros la obligación de establecer en su normativa nacional una prohibición de utilizar en la publicidad de medicamentos destinada al público declaraciones de terceros, cuando estas se referencian de forma abusiva, alarmante o engañosa a testimonios de curación en el sentido del artículo 90 j), esto es, en ningún caso, la publicidad puede sugerir que el usuario puede mejorar su salud mediante la utilización del medicamento y ello con el fin de impedir el consumo de medicamentos cuando su uso no es objetivamente necesario si no existe un problema de salud particular.

En todo caso, corresponde al órgano jurisdiccional nacional apreciar en qué medida la publicidad en el caso concreto, analizada en su conjunto, se refiere a la eficacia terapéutica de los medicamentos. Además, comprobada ésta, hace falta que tal referencia sea abusiva, alarmante o engañosa. 
La actividad publicitaria es información, información veraz, pero sobre todo persuasión y si ésta se basa en la veracidad de los datos del contenido de la publicidad no es ilícita. En todo caso, siendo veraz, debe ir siempre acompañada de una recomendación de acudir al médico o farmacéutico, en tanto en cuanto, el estado individual de cada paciente es variable $y$, por lo tanto, los efectos del medicamento pueden no ser los mismos. No olvidemos tampoco que se trata de medicamentos para los cuales no es necesaria una prescripción médica, lo que significa que no existe un riesgo cierto para la salud.

La Ley establece la distinción entre la publicidad directa al público de los medicamentos sin receta, que, en todo caso, está permitida, aunque con limitaciones y orientaciones a cómo se ha de realizar esta publicidad; y la publicidad directa al público de medicamentos con receta, que está prohibida en cualquier caso. El por qué de esta distinción se sustenta en la mayor peligrosidad que conlleva el uso de medicamentos con receta y los riesgos para la salud del paciente, entendiendo que una publicidad directa al público de los mismos podría llevar a un uso indebido o un uso irracional del medicamento.

Si esto es así, a sensu contrario, ello implica que el uso de un medicamento sin receta conlleva menos riesgos para la salud, pues, ante la dolencia o enfermedad que pretende combatir, el paciente puede acceder al medicamento sin necesidad de que un médico lo prescriba. La publicidad se convierte en una importante herramienta de la información, por lo que la veracidad de la misma es esencial.

c) Prohibiciones específicas:

- Se prohíbe también que la publicidad se dirija exclusiva o principalmente a los niños, cumpliendo así con la normativa de protección del menor en este ámbito específico.

La LGP considera publicidad ilícita «la publicidad dirigida a menores que les incite a la compra de un bien o de un servicio, explotando su inexperiencia o credulidad, o en la que aparezcan persuadiendo de la compra a padres o tutores. No se podrá, sin un motivo justificado, presentar a los niños en situación peligrosas. No se deberá inducir a error sobre las características de los productos, ni sobre su seguridad, ni tampoco sobre la capacidad y aptitudes necesarias en el niño para utilizarlos sin producir daño para sí o para terceros».

La legislación específica va más allá al prohibir cualquier tipo de publicidad de medicamentos dirigida exclusivamente a niños.

- Tampoco puede el medicamento equipararse a un producto alimenticio, cosmético o cualquier otro producto de consumo. Aunque ello ya va implícito en la obligación referida a que el contenido de la publici- 
dad debe reflejar con absoluta claridad que el producto que publicita es un medicamento. Por otra parte, debemos advertir que cualquiera de estos otros productos podría entrañar los mismos o mayores peligros para la salud que un medicamento y tienen, asimismo, una regulación específica que, en materia de publicidad, al margen de lo exigido en la normativa general de publicidad, prohíbe que el mensaje publicitario contenga alusiones a características o propiedades que no posea el producto, o que le atribuya al mismo propiedades curativas o afirmaciones falsas o que induzcan a error(15).

- Se prohíbe la mención en la publicidad destinada al público de una serie de indicaciones terapéuticas: a) Tuberculosis. b) Enfermedades de transmisión sexual. c) Otras enfermedades infecciosas graves. d) Cáncer y otras enfermedades tumorales. e) Insomnio crónico. f) Diabetes y otras enfermedades del metabolismo.

- Se prohíben las primas, obsequios, premios, concursos, bonificaciones o similares como métodos vinculados a la promoción o venta al público de estos medicamentos.

Una prohibición muy acertada, pues de otro modo, puede generarse una dinámica errónea en cuanto a la dispensación de medicamentos y la información que el médico o farmacéutico pueda dar a los pacientes, ya que la decisión no sería del propio paciente conforme a la información de cada producto y a la recomendación del profesional de la salud de modo «independiente».

- Respecto de los productos sanitarios, no es posible realizar publicidad directa o indirecta, dirigida al público en el caso de que un producto esté financiado por el Sistema Nacional de Salud(16). Exclu-

(15) La regulación de los productos cosméticos se establece en el Real Decreto 1599/1997, de 17 de octubre (BOE núm. 261, de 31 octubre), legislación consolidada con diversas modificaciones posteriores. Además, en él se regula la competencia de la Agencia Española de Medicamentos y Productos Sanitarios para vigilar el cumplimiento de las condiciones de publicidad y, la posibilidad de adoptar medidas oportunas, tales como prohibir la puesta en el mercado, ordenar la retirada o someter a condiciones cualquier producto cosmético, cuando éste presente un riesgo para la salud y seguridad de las personas, en condiciones normales o previsibles de uso

(16) Es interesante destacar que en nuestro sistema sanitario la Administración inició un proceso con el fin de fomentar la prescripción y consumo de los medicamentos genéricos, que son aqueIlos que tienen las mismas características terapéuticas que el medicamento original y se presentan con el nombre genérico de su principio activo. El objeto de esta política es reducir el gasto sanitario y farmacéutico. La regulación establece que la financiación (sólo serán objeto de financiación con cargo al Sistema Nacional de Salud las especialidades farmacéuticas cuyos precios no superen la cuantía que para cada principio activo se establezcan reglamentariamente) de las especialidades farmacéuticas financiadas con fondos públicos no excluye la posibilidad de que el usuario elija otra especialidad farmacéutica prescrita por el médico que tenga igual composición cualitativa y cuantitativa en sustancias medicinales, forma farmacéutica, vía de administración y dosificación y de precio más elevado, siempre que, además de efectuar, en su caso, la aportación económica que le corresponda satisfacer de la especialidad farmacéutica financiada por el Sistema, los beneficiarios paguen la diferencia existente entre el precio de ésta y el de la especialidad farmacéutica elegida. 
yéndose también la publicidad de aquellos productos sanitarios que vayan a ser aplicados o utilizados exclusivamente por los profesionales de la salud(17).

Junto a la publicidad de medicamentos que analiza la normativa específica, existen otros productos, que no son medicamentos, pero que tienen una cierta finalidad sanitaria, que son los conocidos como "productos milagro" (18). La publicidad de este tipo de productos tiene una regulación propia en el Real Decreto 1907/1996, de 2 de agosto. Sin perjuicio de las competencias de las Comunidades Autónomas en materia de publicidad, esta norma estatal recoge la competencia de las autoridades sanitarias para que ejerzan el control de la publicidad y la promoción comercial de todos aquellos productos o métodos que se anuncian o se presentan como útiles para el diagnóstico, prevención o tratamiento de enfermedades o desarrollos fisiológicos, adelgazamiento, modificación del estado físico o psicológico, restauración, corrección o modificación de funciones orgánicas u otras pretendidas finalidades sanitarias para que se ajusten a criterios de veracidad. Esta competencia de control se justifica en la protección del derecho a la salud y la seguridad de las personas a través de una adecuada información (19).

\section{Publicidad directa al público de los medicamentos cuyo uso requiera la previa prescripción médica (medicamentos con receta)}

En nuestro Derecho, como hemos expuesto, y en los Estados miembros de la Unión Europea, la publicidad directa al público de los medicamentos con receta está prohibida. Se considera que tales medicamentos deben ser supervisados por un médico o profesional de la salud para permitir su uso porque el paciente no tiene la capacidad suficiente para

(17) Esta prohibición afecta a las empresas fabricantes, distribuidoras o comercializadoras, así como a todas aquellas entidades que puedan mantener un contacto directo con el paciente. Se prohíbe también las primas, obsequios, descuentos, premios, concursos, bonificaciones o similares como métodos vinculados a la promoción o venta al público de dichos productos. Véase J.M. BUSTO LAGO, N. ÁLVAREZ LATA y F. PEÑA LÓPEZ (2010), "Regímenes especiales de publicidad para algunos bienes y servicios", en Grandes Tratados. Reclamaciones de Consumo, Pamplona: Aranzadi.

(18) Sobre el régimen de los productos milagro véase F.M. BOMBILLAR SÁENZ (2014), "Deporte y salud. El fomento de las prácticas deportivas saludables en Andalucía", en Diferentes perspectivas del Derecho Deportivo en Andalucía. Libro Homenaje al Profesor Rafael Barranco Vela, Pamplona: Aranzadi, págs. 139 a 141.

(19) Op. cit.en nota 18 , págs. 3 y ss. 
utilizar por sí mismo el medicamento en condiciones de seguridad. En tanto que esto es así, la prohibición de la publicidad directa al público se justifica en que de tal publicidad puede derivarse un uso irracional del medicamento.

Los medicamentos que requieren una receta médica son aquellos que pueden presentar un peligro, incluso en condiciones normales de uso, si se utilizan sin control médico o aquellos que contengan sustancias o preparados a base de dichas sustancias, cuya actividad o reacciones adversas sea necesario estudiar más detalladamente; así como los que se usen por vía parenteral, salvo excepciones, por prescripción médica.

El fin último es la salvaguarda de la salud pública. Y este mismo fin es el que justifica la prohibición de la publicidad directa al público de los medicamentos con receta, pues la dispensación de los mismos depende de la autorización médica en cada caso concreto. La información y publicidad de los mismos debe hacerse a los profesionales de la salud, para que estén en condiciones adecuadas de recetar el producto (20).

La pregunta que hemos de formularnos es si la prohibición de la publicidad directa al público de los medicamentos con receta garantiza el uso adecuado del medicamento; si es necesaria la prohibición de la publicidad directa al público para la salvaguarda de la salud pública; si con ello se pretende evitar la presión a la que podría verse sometido el profesional de la salud a la hora de recetar un determinado fármaco.

En estos casos el límite debe estar en la concreción del objeto de la publicidad, que, junto al fin lucrativo de la empresa a través de la persuasión, ha de ser el de proporcionar tanto a los médicos como a los pacientes una información educativa precisa sobre las enfermedades y sobre las opciones de tratamiento. El control público y los límites que se impongan deben girar en torno a conseguir un justo equilibrio en el contenido de la publicidad entre los beneficios y riesgos del medicamento, y preservar que la información es veraz.

Ahora bien, la propia evolución-revolución y convergencia de las diversas tecnologías ha propiciado un nuevo escenario de la comunicación en la denominada sociedad digital, que exige un nuevo marco jurídico. La actividad publicitaria ha encontrado en el entorno on-line un modelo de negocio más rentable y con un público potencial más amplio, convirtiéndose en un tipo de publicidad directa al público. Ello nos enfrenta al problema de la eficacia en la regulación on-line.

En este contexto, podemos cuestionar la prohibición absoluta de la publicidad directa de los medicamentos con receta, amparada en la protección del uso racional del medicamento. Ello por dos razones fundamentales:

(20) IRACULIS...... op. cit. 


\section{a) LA CONSIDERACIÓN DE LA ACTIVIDAD PUBLICITARIA COMO DERECHO FUNDAMENTAL}

Sin entrar en el debate de si la actividad publicitaria es libertad de expresión o libertad de empresa, si es o no, en sentido estricto, un derecho fundamental, a lo que nos hemos referido en un apartado anterior, debemos recordar que la mayoría de la doctrina, tanto administrativista como constitucionalista, coincide en que los límites entre los derechos del capítulo II, sección primera, de la Constitución («derechos fundamentales y libertades públicas») y los derechos del capítulo II, sección segunda CE ("derechos y deberes de los ciudadanos»), son muy difusos. Además, también el Tribunal Constitucional ha reconocido el carácter de derecho fundamental tanto de la propiedad privada, como de la libertad de empresa(21).

Por otra parte, muchos de los derechos y valores reconocidos en nuestra Constitución como principios rectores de la política social y económica, entre los que se encuentra el derecho a la salud, o el derecho a un medio ambiente adecuado, también son considerados verdaderos derechos fundamentales de configuración legal.

Ello nos lleva, ante el conflicto de derechos planteado, a la aplicación necesaria de la teoría de los límites de los derechos constitucionales, sin anular uno en beneficio de otro, sino buscar el justo equilibrio entre ambos. De ahí, que cuestionemos si la prohibición absoluta de la publicidad de los medicamentos con receta no resulta una medida demasiado restrictiva que anula por completo un derecho que, sea libertad de expresión o sea libertad de empresa, es considerado un derecho fundamental, rompiéndose el necesario equilibrio que persigue la teoría de los límites de los derechos constitucionales (22).

En todo caso, la normativa en materia de publicidad de medicamentos gira en torno al segundo elemento, esto es, la información que se proporciona del producto, del medicamento. En este sentido, la actividad publicitaria podría ser considerada también como derecho funda-

(21) Así, en SSTC 46/1983, 118/1983, 227/1993. En la primera de ellas, el TC reconoce que la libertad de empresa es un derecho fundamental, aunque no esté protegido por el recurso de amparo, pues tiene un contenido esencial garantizado frente al legislador según lo establece el art. $53 \mathrm{CE}$.

Véase Y. GÓMEZ (2015), Constitucionalismo multinivel. Derechos fundamentales, Sanz y Torres. R. RIVERO ORTEGA (2013), Derecho Administrativo Económico, Madrid: Marcial Pons; de este mismo autor también, "La Libertad de Comercio", ponencia presentada en el Congreso de la Asociación Española de Profesores de Derecho Administrativo, Cádiz 6 de febrero de 2009.

Así también, G. ARIÑO ORTIZ (1995), Principios constitucionales de la libertad de empresa. Libertad de comercio e intervencionismo administrativo, Madrid: Marcial Pons-IDELCO.

(22) Véase L. MARTíN-RETORTILLO (1988), «Régimen constitucional de los derechos fundamentales», en Derechos Fundamentales y Constitución, Madrid: Cuadernos Civitas. L. DE LUQUE (1993), "Los límites de los derechos constitucionales", Revista del Centro de Estudios Constitucionales, 14. Y. GÓMEZ (2015), Constitucionalismo multinivel. Derechos fundamentales, op. cit. 
mental del artículo 20 CE que reconoce el derecho a recibir y comunicar información.

\section{b) EL DERECHO A LA INFORMACIÓN DE LOS USUARIOS}

Junto a lo anterior, la actividad publicitaria, entendida como información, aunque con la intención de vender, radica en el derecho de los pacientes y potenciales pacientes a conocer la información de todos los medicamentos. A través de la publicidad de los medicamentos, se logra satisfacer el derecho a la información de los usuarios, sin que ello conlleve un uso irracional del medicamento publicitado. En primer lugar, porque para su consumo es necesaria la prescripción médica. Tampoco, la publicidad puede conducir a que se distorsione de algún modo la relación médico-paciente. Incluso, puede permitir al profesional de la salud, su conocimiento de los nuevos medicamentos en el mercado. Pero su profesionalidad a la hora de prescribir un medicamento no queda afectada en modo alguno.

Los límites a este derecho, deben enfocarse en exigencias en cuanto a la presentación de la información, de sus contenidos $y$, dependiendo del medio empleado, el lugar en el que debe aparecer la información considerada esencial.

Si bien, además de estas obligaciones necesarias desde el punto de vista de la información de la actividad publicitaria, no existe una garantía total de la objetividad del anunciante, por lo que considero también imprescindible que se ofrezca al consumidor una información independiente, completa y accesible, por la Administración Pública competente, a través de un servicio de información médica, al margen de los intereses comerciales. Uno de los elementos a desarrollar es el de la accesibilidad de la información, que deberá trascender a la propia oficina de farmacia, o establecimiento en el que se dispensen los medicamentos.

En mi opinión, la prohibición absoluta del derecho a realizar publicidad de este tipo de medicamentos, no se justifica en la salvaguarda del derecho a la salud; no existe una relación directa entre prohibición de publicidad y uso racional del medicamento. Quizás existen otros inconvenientes que pretende evitarse con esta prohibición, más relacionados con el precio real de los medicamentos, muy elevado, y el alto porcentaje de financiación con fondos públicos. Por otra parte, no es baladí pensar que la publicidad directa al público puede no ofrecer una información objetiva sobre los riesgos y beneficios de las distintas opciones de tratamiento con el fin de ayudar al consumidor a tomar parte en las decisiones médicas. 


\section{La publicidad directa al público de medicamentos con receta en Estados Unidos}

\section{El debate sobre la permisión de la publicidad directa al público de medicamentos con receta}

En Estados Unidos está permitida la publicidad directa al público de los medicamentos con receta, considerados como aquellos que deben ser supervisados por un médico profesional a efectos de garantizar su uso porque el paciente no tiene la capacidad suficiente para utilizar por si mismo el medicamento en condiciones de seguridad.

Pero, precisamente con el fin de mejorar la satisfacción del paciente, el cumplimiento de los tratamientos $y$, en última instancia, los resultados de la atención de la salud, se permite dar información directa al público a través de la publicidad de los medicamentos con receta, en tanto en cuanto, ello permite que los consumidores y potenciales consumidores, si están bien informados, pueden convertirse en usuarios más seguros, más rentables y más racionales de los medicamentos recetados (23).

El sector farmacéutico supone uno de los negocios más beneficiosos en muchos países. Bien es cierto que, el descubrimiento, el desarrollo y la fabricación de medicamentos conlleva, desde luego, muchos años de trabajo sin beneficio, e, incluso, muchas de las investigaciones no llegan a tener el resultado deseado. De ahí, el alto coste que un nuevo medicamento llega a tener y la importancia de la publicidad a los efectos de dar a conocer el medicamento y sus características a un público más amplio, y no solo a los profesionales de la información, con el claro objetivo de lograr no ya un mayor beneficio, sino mucho más allá de la recuperación de costes de la investigación (24).

La industria farmacéutica es muy competitiva y se mueve en un entorno que promueve y premia la innovación; la competencia lo es a diferentes niveles, tanto nacional, como internacional (25). La competencia es

(23) Véase THIMOTY S. HALL (2003), «The promise and peril of direct-to-consumer prescription drug promotion on the Internet", De Paul Journal of Health Care Law, 7 DePaul J. Health Care L. 1, págs. 1 a 2.

(24) Hay una tasa muy alta de fracaso de los medicamentos para los que se solicita su aprobación por la FDA, por lo que es común que las empresas tengan una serie de medicamentos en desarrollo aunque la tasa de éxito sea baja. La FDA es uno de los principales organismos reguladores encargado de establecer los requisitos y garantizar el cumplimiento de las cuestiones relacionadas con los productos de las compañías farmacéuticas. El proceso desde el desarrollo hasta la comercialización es muy largo (entre 8 y 20 años) y costoso y se integra de diversas etapas hasta su aprobación: aplicación de nuevos fármacos en investigación; ensayos clínicos; nueva aplicación de fármacos; seguridad y eficacia; fabricación, almacenamiento y etiquetado; marketing, publicidad y promoción; requisitos post-mercado; vigilancia post-comercialización. Véase Pharmaceutical Industry Guide, 2013. Practical Law Practice Note 2-518-8595 (2013).

(25) Históricamente la competencia era entre empresas de Estados Unidos, pero cada vez más las empresas farmacéuticas se enfrentan a la competencia de fabricantes fuera de Estados Uni- 
un factor esencial para justificar el recurso a la publicidad como medio de dar a conocer el producto y con el fin de vender, más allá de ser considerado un medio de información al paciente con el objetivo de mejorar la relación médico-paciente.

En Estados Unidos se establece la diferencia entre los medicamentos sin receta y los medicamentos con receta, estando permitida la publicidad directa al público en ambos casos. Esto no quiere decir que no exista un debate acerca de los riesgos que conlleva esta regulación, así como también de los beneficios, tanto a nivel doctrinal, como también, federal.

Son dos los organismos implicados en esta actividad. En primer lugar, la competencia material en materia de medicamentos la tiene la Administración de Alimentos y Medicamento (FDA). Y la competencia general en materia de publicidad corresponde a la Comisión Federal de Comercio (FTC). Si bien, cuando se trata de publicidad de medicamentos, el Congreso estableció diferentes requisitos según se trate de medicamentos sin receta o de medicamentos con receta. Básicamente, existe un reparto de la competencia entre ambas Agencias, de manera que la FDA tiene la competencia para supervisar los anuncios publicitarios de los medicamentos con receta, mientras que la FTC supervisa la publicidad de los medicamentos sin receta o de venta libre(26).

\title{
2. Breve referencia a la competencia en materia de medicamentos y de publicidad en Estados Unidos: La Administración de Alimentos y Medicamentos (FDA) y la Comisión Federal de Comercio (FTC) (27)
}

Como hemos expuesto, el organismo competente para la regulación de los medicamentos es la Agencia de Alimentos y Medicamentos (FDA);

\begin{abstract}
dos, particularmente de, India en el desarrollo y producción de medicamentos genéricos. Véase "Pharmaceutical Industry Guide: 2013», en la que se explica cómo los genéricos son una fuente importante de competencia para los medicamentos de marca. Las compañías farmacéuticas que han invertido en el desarrollo de un fármaco y han logrado obtener la aprobación de la FDA tienen derecho a un período de exclusividad de comercialización; este período es determinado según el tipo de medicamento aprobado (por ejemplo, los medicamentos huérfanos tienen un período de 7 años, y los nuevos medicamentos químicos tienen un período de 5 años). Además, las compañías también están protegidas por la patente y una vez que ésta expira y finaliza el período de exclusividad, un producto genérico competidor entre en el mercado con mucha rapidez. La pérdida de exclusividad y de la protección generalmente conduce a una reducción de las ventas en un corto período. Las compañías genéricas suelen ofrecer el medicamento a un precio mucho menor, pues no tienen el costo de la investigación y el desarrollo asociado al descubrimiento del fármaco. El impacto competitivo con medicamentos de marca es considerable.
\end{abstract}

(26) B. BUECHNER (2013), "A Comparative Legal Analysis of Social Media Advertising of Drugs in Germany and the United States», Food and Drug Law Journal , 68 Food Drug L.J. 259.

(27) www.fda.us. FDA: Food and Drug Administration. FTC: Federal Trade Commission. Ambas Agencias Federales. 
es una Agencia dentro del Departamento de Salud y Servicios Humanos, que funciona a través de la Oficina del Comisionado y cuatro direcciones que supervisan las funciones básicas de la Agencia: Productos Médicos y Tabaco, Alimentos, Operaciones y Regulaciones Globales y Operaciones.

La norma básica de regulación de los medicamentos es la Ley Federal de Alimentos, Medicamentos y Cosméticos (FDCA); al amparo de esta norma tiene la FDA la competencia en materia de publicidad directa al público de los medicamentos con receta; esto es, tiene la competencia de supervisar la publicidad y comprobar que ésta no sea inadecuada o engañosa, en cuyo caso, se deriva la responsabilidad penal o civil (28).

Por su parte, la FTC es la Agencia competente, con carácter general, para la protección de los derechos de los consumidores y la eliminación y prevención de prácticas que atentan contra la libre competencia. En materia de medicamentos tiene también competencia para regular la publicidad de los productos farmacéuticos; hasta 1962 su competencia se extendía a los anuncios de todo tipo de medicamento, pero a partir de esta fecha la competencia sobre publicidad de medicamentos con receta fue transferida a la FDA.

Teniendo en cuenta las competencias confluyentes de ambas Agencias, con el fin de evitar un solapamiento innecesario de competencias, y una duplicidad de esfuerzos, ambas Agencias firmaron un acuerdo conforme al cual, la FTC mantiene su competencia para regular toda la publicidad de medicamentos, excepto la referida a los medicamentos con receta que queda en manos de la FDA. Aún así, la FTC desempeña un importante papel en la regulación de la publicidad de los medicamentos en general. Los medicamentos sin receta o de venta libre están regulados por esta Agencia, aunque la FDA tienen competencia en materia de etiquetado de tales medicamentos. Por otra parte, en 2000 publicó la Guía "Dot Com Disclosures" para las empresas que se anuncian por Internet; esta guía fue revisada y actualizada en 2011 y publicada en 2013 (29). Aunque tiene carácter general, plantea cuestiones interesantes sobre la regulación de la publicidad en Internet en general que es relevante para la regulación por la FDA de la publicidad de medicamentos con receta en Internet.

En lo que respecta a la competencia de la FDA, las primeras regulaciones de la FDA sobre publicidad de medicamentos se enfocaron a conseguir que los médicos dispusieran de una adecuada información

(28) Véase THIMOTY S. HALL (2003), "The promise and peril of direct-to-consumer prescription drug promotion on the Internet», op.cit., pág. 2.

(29) FTC, "Dot Com. Disclosures. How to Make Effective Disclosures in Digital Advertising", 2013, en www.ftc.gov. 
para poder realizar las oportunas prescripciones del medicamento y se centraron en exigencias de exponer las contraindicaciones conocidas, los riesgos, los efectos secundarios; iban dirigidas a los profesionales de la salud, pues se consideraba que tenían mayor capacidad para dar la información sobre los riesgos de los medicamentos con receta al paciente (30).

A medida que los pacientes se involucran más en su tratamiento, las empresas farmacéuticas tratan de ampliar la promoción de sus productos directamente a los consumidores. Tras un período de estudio e investigación sobre los efectos de la publicidad directa al público de medicamentos con receta, la FDA resolvió su posición favorable a esta publicidad, exigiendo que los anuncios respectivos cumplan con los mismos requisitos legales que los dirigidos a los profesionales de la sa$\operatorname{lud}(31)$.

(30) Se aplica la doctrina del intermediario, es decir, se entiende que el médico es un «intermediario con conocimiento" entre la empresa y el paciente, luego está en mejor posición para comprender los riesgos y los beneficios del medicamento en cuestión y es capaz de dar esa información al paciente. La empresa farmacéutica debe informar al médico de los riesgos de un medicamento con receta para evitar la responsabilidad.

Véase J. WEST (2012), "Note \& Student work: National marketing gone unintentionally globlal: Direct-to- Law, 11 J. Int'l Bus. \& L. 405, págs.. 4 y ss. Hace referencia al cambio de planteamiento con el desarrollo de la píldora anticonceptiva; en el caso Massachusetts MacDonald v. Ortho Pharmaceutical Corp., el tribunal resolvió que los anticonceptivos orales tienen características peculiares que exigen una excepción a la regla del intermediario. E indica que mientras que la participación del paciente en la toma de decisiones sobre el uso de un medicamento recetado para tratar una enfermedad es mínima o nula, la píldora no se prescribe para solucionar un problema médico, sino que se administra a las mujeres sanas de forma electiva, permitiendo al paciente tener un papel más activo en la elección de la forma de control de la natalidad que va a utilizar. Normalmente la prescripción del médico se hace en la cita anual correspondiente, recibiendo la paciente una receta para todo el año, por lo que la capacidad de supervisión del médico es mínima. Así, el Tribunal concluye que en el caso de los anticonceptivos la empresa tiene la obligación de advertir directamente a los pacientes de los riesgos de ciertos medicamentos que tienen un fin principalmente preventivo.

(31) El primer anuncio de medicamento con receta dirigido al consumidor fue publicado en 1981 por Boots Pharmaceuticals, una compañía farmacéutica británica cuya filial americana fue situada en Shreveport, Luisiana, para el producto del ibuprofen, Rufen. En ese mismo año, Merck Sharp \& Dohme lanzó el segundo anuncio impreso de publicidad directa al público, para Pneumovax, su vacuna contra la neumonía. Más tarde, otras empresas farmacéuticas voluntariamente propusieron a la FDA anuncios de publicidad directa al público. Se trataba de un nuevo supuesto para el que la FDA necesitaba tiempo para su estudio y aprobación. Por lo que en 1982, se solicitó a la industria farmacéutica una moratoria voluntaria que permitiera a la FDA su investigación. Varios de esos estudios mostraron que los consumidores mantenían más información sobre los beneficios que sobre los riesgos del medicamentos y que requerían más información sobre los medicamentos reservados, revelando una posición favorable a la publicidad directa al público de medicamentos con receta.

Véase F.B. PALUMBO y C.D. MULLINS (2002), "The Development of Direct-to-Consumer Prescription Drug Advertising Regulation", Food and Drug Law Journal, 57 Food Drug L.J. 423, págs. 2 a 3.

J. WEST (2012), «Note \& Student work: National marketing gone unintentionally globlal: Direct-toconsumer advertising of pharmaceutical products and the Internet", Journal of International Business and Law, 11 J. Int'I Bus. \& L. 405, págs.. 4 y ss. 
La regulación de la publicidad de medicamentos por parte de la FDA distingue entre (32):

a) Product Claim Advertisementes, Anuncios de reclamo, definidos como el único tipo de anuncio que menciona un medicamento y expone sus riesgos y beneficios. No deben ser falsos ni engañosos y el lenguaje ha de ser claro y comprensible para todos los consumidores. Con independencia del soporte, deben incluir en la parte principal del anuncio una serie de contenidos: nombre del medicamento (marca y genérico); al menos un uso aprobado por la FDA para el medicamento; los riesgos más significativos y presentar de modo equilibrado la relación riesgos-beneficios; así como también dar un breve resumen sobre el medicamentos que, generalmente refiere todos los riesgos enumerados en la información de prescripción aprobada (33).

b) Anuncios de recordatorio, los que dan el nombre del medicamento, pero no los usos de mismo, pues se supone que el usuario conoce ya el uso del medicamento. No tiene por qué incluir los riesgos; tampoco se indica para qué sirve, ni cómo funciona. Tampoco pueden sugerir nada acerca de los beneficios. No se permite este tipo de anuncio para ciertos medicamentos con receta a los que se asocian riesgos graves, los cuales deben tener una advertencia especial y deben incluir todos los riesgos.

c) Anuncios de búsqueda de ayuda: son los que describen una enfermedad, pero no recomiendan o sugieren un tratamiento farmacológico específico. Animan a las personas que padecen los síntomas que describen a acudir a su médico y pueden incluir el nombre de una compañía farmacéutica, así como proporcionar un número de teléfono para obtener información. Si se hacen correctamente, estos anuncios no se consideran anuncios de medicamentos y se re-

(32) Esta regulación de la publicidad directa al público de los medicamentos con receta se encuentra en el "Code of Federal Regulations, 21 CFR-202 (2011), siendo el más importante el «brief summary" (breve resumen exigido), que implica la presentación de una declaración breve y veraz de los efectos secundarios, las contraindicaciones y eficacia del medicamento. Este requisito no se entiende cumplido cuando la declaración presentada es falsa o engañosa en alguno de sus contenidos; cuando no presenta un justo equilibrio entre la efectividad y los efectos secundarios o contraindicaciones; o hay error en mostrar las consecuencias derivadas del consumo del medicamento. Información: www.fda.gov

Así también, F.B. PALUMBO, ...., op. cit. ut. supra., en general la alusión a los tipos de anuncio a lo largo del artículo.

(33) Con la Ley de Enmiendas de la FDA de 2007, se exige que los anuncios impresos incluyan una declaración del tipo "le recomendamos que informe a la FDA de los efectos secundarios negativos de los medicamentos con receta; visite MedWatch o llame al 1-800-FDA-1088". Sobre los anuncios de televisión, radio, o teléfono, se exige que incorporen los riesgos más importantes en la declaración principal, así como que se indiquen las fuentes a las que el consumidor puede acudir para obtener una información más completa (médico, número de teléfono gratuito, sitio web, ...). 
gulan por la FTC; pero si se recomienda o sugiere el uso de un medicamento, se considera anuncio de reclamo de producto y debe cumplir con las exigencias de la FDA.

La FDA ha considerado que las regulaciones existentes eran suficientes para proteger el derecho a la salud y seguridad de los consumidores, aún en el caso de la publicidad directa al público de los medicamentos con receta. Lo que dio lugar a la mencionada exigencia de que en la publicidad de los medicamentos con receta se incluyera toda la información de advertencia y efectos secundarios en ese breve resumen, con la dificultad de presentarlo en un anuncio en televisión o radio. Por ello se procede a una revisión en 1997 de la regulación en estos casos, aprobándose una Guía dirigida a la Industria, a través de la cual se hace una interpretación que tuvo por efecto relajar esas restricciones previas, de manera que un anuncio por televisión no tiene por qué incluir el "breve resumen" de la información diseñada para los medicamentos con receta, siendo suficiente con que se muestre un justo equilibrio entre los riesgos y los beneficios asociados al medicamento. La Guía diferencia la publicidad telefónica de la publicidad por radio o televisión y, a pesar de no disponer de una normativa específica para la promoción por Internet de medicamentos con receta, la FDA ha venido aplicando las regulaciones existentes en el entorno on-line, exigiendo a las empresas que adapten o retiren los anuncios que no muestran un justo equilibrio entre los riesgos y beneficios; retiren el material obsoleto alojado en un sitio web promocional; detecten las afirmaciones engañosas o la promoción de usos de medicamentos no aprobados (34).

Junto con la regulación establecida por la FDA y la FCT, se aplica la legislación sobre daños y responsabilidad civil, siendo la cuestión más relevante el efecto que tiene en el mercado de la publicidad directa al público de los medicamentos con receta y la aplicación de la denominada "Learned Intermediary Rule».

Como regla general, la legislación de responsabilidad civil establece la responsabilidad objetiva de los daños causados por los productos que se introducen en el mercado o pasan por manos de un fabricante o vendedor particular y puede basarse en el diseño defectuoso del producto en cuestión o en la omisión del fabricante de la necesaria advertencia al consumidor de los riesgos derivados del uso del producto. Ahora bien, en los casos de los considerados "productos peligrosos", como el caso de los

(34) Véase THIMOTY S. HALL (2003), "The promise..., op. cit., págs. 5 y ss. Alude a los cuatro métodos que establece la FDA con el fin de obtener una adecuada información: 1) establecer un número de teléfono gratuito al que los consumidores puedan llamar y solicitar una copia de la información o le sea leída por teléfono; 2) determinar un sitio web para proporcionar la información de etiquetado; 3 ) indicar al consumidor que consulte con su médico o farmacéutico; 4) proporcionar un medio cuando no se disponga de tecnología suficiente para obtener tal información. 
medicamentos con receta, se establece una excepción a la responsabilidad objetiva, siempre y cuando se haya dado una clara advertencia sobre la peligrosidad del producto. Los tribunales han aplicado la "Learned Intermediary Rule» con el fin de no imputar la responsabilidad a los fabricantes de medicamentos por los daños causados por los medicamentos, siempre y cuando hubieran advertido a los médicos adecuadamente de los peligros conocidos de los medicamentos. Aunque no se trata de una inmunidad absoluta de la responsabilidad de los fabricantes de medicamentos con receta, pues los tribunales han sostenido que esta regla no se aplica, y por lo tanto, los fabricantes tienen la obligación de dirigir esta advertencia sobre los riesgos del medicamentos directamente al consumidor, en situaciones de vacunas masivas. Si bien es cierto, la obligación impuesta por la FDA a que esta información se de directamente a los consumidores de ciertos medicamentos con receta ha justificado que algunos tribunales puedan no aplicar esta regla, en cuanto que las advertencias del producto deben ir dirigidas al paciente (35).

(35) Véase THIMOTY, ..., op. cit., págs. 6 y ss. Así también de este mismo autor, "Symposium on Health Care Technology: Regulation and reimbursment: regulating direct-to-consumer advertising with tort law: Is the Law finally catching up with the market?", Western New England Law Review, 31 W. New Eng. L. Rev. 333 (2009). Véase también WEST, Jackeline, ..., op. cit., págs. 5 y ss.

No faltan críticas a esta regla, sobre todo teniendo en cuenta la publicidad directa al público cuando el medio es Internet. En ambos estudios se menciona el caso "Pérez v. Wyeth Labs., Inc.» Ilevado por la Corte Suprema de Nueva Jersey, en el que se reconoció una excepción a la "learned intermediary rule». La compañía había realizado una amplia publicidad directa al consumidor del medicamento (anticonceptivo Norplant). Los afectados alegaban daños por los efectos secundarios y cicatrices causadas por la remoción del dispositivo. En este caso, muchos médicos publicaron informes en revistas médicas sobre las dificultades de la eliminación del fármaco, efecto al que no se aludía en la publicidad, así como tampoco a otros efectos secundarios. El Tribunal dio tres razones por las que se excepciona la regla: 1) el cambio a una ética centrada en el paciente, a través de la doctrina del consentimiento informado y el derecho del paciente a participar en la toma de decisiones en el ámbito de la atención de la salud; 2) los efectos de la atención administrada en la relación médico-paciente, con una disminución del tiempo de que dispone el médico para atender al paciente; 3) el gran desarrollo de la comunicación entre los fabricantes de medicamentos a los pacientes y potenciales pacientes a través de los diversos medios de comunicación. A pesar de ello, el cumplimiento de las directrices impuestas por la FDA sobre la publicidad directa al público de medicamentos con receta era irrefutable y corresponde al demandante probar que el fabricante no cumplió con las directrices de la FDA y que el material publicitario era legalmente inadecuado por alguna razón. Véase Kathryn Bi (2015), "Comments: What Is "False or Misleading" Off-Label Promotion?", University of Chicago Law Review, 82 U. Chi. L. Rev. 975; J. SHAEFFER (2003), "Prescription Drug Advertising - Should States Regulate What is False and Misleading?", Food and Drug Law Journal, 58 Food Drug L.J. 629. Véase también A. PORTER (2012), "Old Habits Die Hard: Reforming the Learned Intermediary Doctrine in the Era of Direct-to-Consumer", McGeorge Law Review, 43 McGeorge L. Rev. 433, en el que se exponen las excepciones a esta doctrina; A. L. FOREMAN (2001), "Web of manipulation: The Learned Intermediary doctrine and direct-to-consumer advertising on the world wide web", The John Marshall Law Review, $35 \mathrm{~J}$. Marshall L. Rev. 97, en este se refiere a dos excepciones a esta doctrina y cómo afecta a la relación médico-paciente, especialmente se refiere a la publicidad de medicamentos recetados en los sitios web; H. HARRELL (2010/2011), "Direct-to-Consumer Advertising of Prescription Pharmaceuticals, the Learned Intermediary Doctrine, andFiduciary Duties», Indiana Health Law Review, 8 Ind. Health L. Rev. 69. 
En Estados Unidos, existe una regulación muy flexible de la publicidad directa al público de los medicamentos con receta, $\mathrm{y}$, a pesar de los esfuerzos de la FDA en establecer directrices a las compañías farmacéuticas y fabricantes de medicamentos que, en el plano teórico, bastarían para lograr el objetivo esencial de esta publicidad, cual es, satisfacer el derecho de información del paciente, la educación para el adecuado cuidado de su salud y la mejora de la relación médico-paciente; sin embargo, la realidad muestra todo lo contrario y la FDA ve limitadas sus funciones a la hora de accionar frente a los incumplimientos de las empresas al hacer publicidad de tales medicamentos. En muchos casos, los riesgos del consumo de un medicamento son, incluso, mayores a los beneficios, en su mayor parte teóricos, y aún así, su publicidad es permitida y aprobada por la FDA(36).

El debate persiste y los argumentos a favor y en contra de la publicidad directa al público de los medicamentos con receta son variados. Así:

-Frente al beneficio que supone la mejora de la elección del paciente al disponer de más información, lo que permite darle una mayor autonomía; el problema de que la información dada no reúne los parámetros de calidad y cantidad necesarios para satisfacer el derecho a la información del paciente.

-Frente a la mejora de la competencia de los médicos, en tanto que la publicidad les permite (y obliga) a estar al día en los nuevos desarrollos, el problema de la disminución de su competencia real, pues determinados medicamentos dispensados con receta con el objetivo de proteger la salud, se convierten más en un estilo de vida que en una opción médica.

-Frente a la mejora de la relación médico-paciente, en tanto que el paciente informado permite aliviar el papel del médico como educador, el problema de las promociones para desear ciertos medicamentos, lo que puede interferir en la capacidad del médico para elaborar un juicio independiente en nombre del paciente.

Si bien, los efectos de la publicidad directa al público de los medicamentos con receta pueden ser más graves debido a los conflictos de intereses entre los médicos y las empresas farmacéuticas, pues, en gran medida, los médicos dependen de los subsidios de la industria farmacéutica, de modo que subyace una relación entre los médicos ejercientes y la industria farmacéutica. Aunque los médicos deciden finalmente la prescripción o no en cada caso particular, lo cierto es que están sometidos a una gran presión que puede influir en su decisión.

(36) Véase M.M. LIPMAN (2006), "BIAS in direct-to consumer advertising and its effect on drug safety", Hofstra Law Review, 35 Hofstra L. Rev. 761, págs. 4 y 5. 
En Estados Unidos es difícil limitar esta actividad publicitara teniendo en cuenta la protección constitucional del derecho a la libertad de expresión comercial. Pero a falta de una prohibición absoluta, sería necesario y conveniente establecer algunas restricciones, en el sentido de fortalecer las competencias de la FDA en cuanto al control de la publicidad y comprobación del cumplimiento del requisito del justo equilibrio entre riesgos y beneficios, entre otros(37). Lo que debe completarse con un adecuado y más riguroso régimen sancionador.

\section{Un apunte sobre la publicidad de los medicamentos en el entorno on-line}

Especial interés reviste la regulación en el entorno on-line, en el que las prácticas publicitarias son muy variadas y, aunque en Internet la línea divisoria entre publicidad y venta es difusa, haremos referencia solo a la publicidad, una alternativa que, comparada con los medios de publicidad tradicionales ofrece más ventajas a las empresas en cuanto a rentabilidad (38). Si Internet puede ser un mejor medio para la publicidad, es necesario, no obstante, una adecuada regulación. Y, precisamente, uno de los problemas más destacados es el cómo regular, toda vez que Internet tienen un carácter transnacional. En este sentido, la autorregulación tiene mucho que decir.

En estos casos, cuando la publicidad del medicamento se hace a través de Internet, surge la cuestión de la legislación aplicable, toda vez que la publicidad puede originarse en un país y el destinatario estar en otro distinto. Puede optarse por exigir un control en el origen o en el destino de la comunicación (39). En el ámbito de la Unión Europea se ha establecido el principio general del control en el origen (40), incorporado a nues-

(37) La FDA no revisa la publicidad antes de su publicación; las directrices aprobadas siguen siendo desarrolladas con el fin de maximizar los beneficios y minimizar los riesgos asociados a la publicidad directa al público de los medicamentos con receta.

(38) Sobre la regulación de la venta a distancia al público, a través de sitios web, de medicamentos de uso humano no sujetos a prescripción médica, véase F.M. BOMBILLAR SÁENZ (2016), "Receta médica electrónica y venta de medicamentos online», en PÉREZ GÁLVEZ, J.F. (dir.), Salud electrónica. Perspectiva y realidad, Valencia:Tirant lo Blanch, págs. 221 y ss.; C. BAES (2010), "La venta de medicamentos por Internet: un nuevo reto para los Estados miembros de la Unión Europea», en BARRANCO VELA, R. (dir.), El acceso al medicamento. Retos jurídicos actuales, intervención pública y su vinculación al derecho a la salud, Granada: Comares, págs.. 163 y ss.

(39) Véase A. PUERTO MENDOZA (2015), Introducción al Derecho de Internet. Régimen jurídico de los contenidos digitales, Madrid: Centro de Estudios Financieros, págs. 207 y ss. Como indica el autor, una de las singularidades del entorno digital es la relativa a la "ubicuidad de la información", toda vez que cuando la información se difunde en la Red, está disponible desde cualquier equipo con independencia de dónde se encuentre físicamente.

(40) Directiva 2000/31/CE del Parlamento Europeo y del Consejo, de 8 de junio de 2000, relativa a determinados aspectos de los servicios de la sociedad de la información, en particular, el comercio electrónico en el mercado interior. 
tra legislación a través de la Ley de los Servicios y la Sociedad de la Información y del Comercio electrónico (LSSI) (41).

La legislación aplicable a la publicidad a través de Internet, junto a la LSSI, es también la legislación general y específica en materia de publicidad. Como es lógico, la legislación de control de publicidad y publicidad ilícita ha de aplicarse en cualquier caso, con independencia del medio o soporte de la misma. El engaño o la falsedad es ilegal, sea cual sea el medio; por lo que las obligaciones del prestador y las garantías del consumidor han de ser las mismas.

Pero la peculiaridad del medio hace difícil una regulación homogénea, por lo que debe buscarse la estabilidad y la seguridad jurídica, también en los mecanismos de autorregulación y en los principios de cooperación internacional. Más aún cuando las posiciones legales sobre el tema concreto, la publicidad directa al público de medicamentos con receta pueden ser antagónicas.

Esta preocupación por la regulación del entorno on-line está presente también en Estados Unidos. Con carácter general, la FTC, junto con la regulación general, ofrece una orientación específica, a través de normas o guías, para que las empresas cumplan con sus obligaciones legales y permita establecer las mismas garantías en las promociones a través de Internet. En todo caso, la legislación obliga a que la publicidad sea veraz y no engañosa; y recomienda algunas técnicas como, entre otras, no ocultar la información relevante en la parte inferior de las páginas, sin hacer alusión a ello en la parte visible; si se utiliza un hipervínculo, que sea absolutamente claro el enlace y calificado de modo que permita dar a conocer la importancia de la información que conlleva, con un lenguaje accesible y comprensible para los usuarios (42).

Cuando el objeto de la publicidad directa al público son los medicamentos con receta, además de la utilidad de estas recomendaciones elaboradas por la FTC, la competencia la tiene la FDA, regulador principal en este ámbito y le corresponde, por lo tanto, acomodar las legislaciones al

(41) La LSSI se aplica a los prestadores de servicios establecidos en España y los servicios prestados por ellos. Se entiende que un prestador está establecido en España cuando su residencia o domicilio social esté en España y lleve desde España la gestión administrativa y dirección de los negocios. También se aplica cuando los servicios se ofrezcan a través de un establecimiento permanente situado en territorio español y este requisito se cumple si el prestador o alguna de sus sucursales se haya inscrito en algún registro público español a efectos de adquirir la nacionalidad española. Hay dos excepciones en las que se aplica el control en destino; de un lado, cuando el prestador está establecido en otro Estado miembro de la Unión Europea o el EEE y se afecte a unas materias concretas, las del artículo $3 \mathrm{LSSI}$; y cuando el establecimiento del prestador se encuentre fuera de los territorios anteriores y se den las circunstancias del artículo 4 LSSI.

(42) Guide "Dat Com. Disclosures»..., op. cit. Véase también Y.T. YANG y B. CHEN (2014), "Legal Considerations for Social Media Marketing by Pharmaceutical Industry», Food and Drug Law Journal, 69 Food Drug L.J. 39, págs.6. 
entorno on line, garantizando la misma protección que en otros medios, y preservando la relación médico-paciente, de manera que el acceso a la información divulgada a través de Internet, no llegue a distorsionar dicha relación. Algunos autores sostienen que una prohibición absoluta de la publicidad de los medicamentos con receta no es la solución, aunque ello evitaría muchos abusos; pero ello no sería posible, precisamente por el carácter extraterritorial de Internet, que hace que las leyes nacionales pierdan eficacia más allá de sus fronteras (43).

En mi opinión, este es un factor muy importante a tener en cuenta a la hora de justificar la prohibición absoluta de la publicidad directa al público de los medicamentos con receta. La facilidad de acceder a la información disponible en Internet permite a los usuarios conocer la existencia de los diversos medicamentos y los tratamientos para los que se utilizan. Sin embargo, no existe la misma garantía legal impuesta a la publicidad en otros medios. Por otra parte, es posible la difusión de información a través de las redes sociales sobre los efectos negativos derivados del uso de un determinado medicamento con receta, en un caso particular, que puede repercutir negativamente en la empresa, y generar una alarma innecesaria, lo que se evitaría o, al menos, se reduciría su impacto, si la promoción del medicamento se permitiera, dentro de las exigencias legales y entendida como instrumento para nutrir el derecho a la información del usuario.

Si en la actual sociedad digital el derecho a la información es un principio esencial, los esfuerzos regulatorios deben encaminarse a lograr que este derecho se vea satisfecho en condiciones de calidad y fiabilidad, más aún cuando se trata de productos inevitablemente peligrosos y es necesario que se refleje una clara relación de riesgos y beneficios derivados de su uso.

En este sentido, y advirtiendo la preocupación existente sobre la publicidad de los medicamentos tanto si la regulación es estricta o flexible, como el caso de Estados Unidos, el instrumento de la autorregulación puede conseguir una homogeneidad válida en el para los diversos regímenes jurídicos.

La autorregulación es esencial en este ámbito. $Y$ debemos destacar cómo en nuestro modelo de farmacia Mediterráneo, la importancia otorgada al circuito oficinal y al consejo farmacéutico, así como el papel confiado a los médicos y farmacéuticos a este respecto, los convierte en engranajes de un entramado normativo que pretende tutelar la salud pública, el uso racional del medicamento y, ello lleva a que muchos entiendan que choca con prácticas publicitarias que puedan incitar a un con-

(43) Así, THIMOTY, ..., op. cit., pág. 14. 
sumo abusivo de medicamentos. Sin embargo, puede ser todo lo contrario, pues precisamente la asunción de este papel conduce a la realización de una actividad publicitaria encaminada a procurar un uso racional del medicamento. Es interesante mencionar el sistema de autorregulación de Farmaindustria, a través del Código de Buenas Prácticas de la Industria Farmacéutica, cuyo ámbito de aplicación cubre todas las formas de promoción de los medicamentos de prescripción; de interrelación entre las compañías farmacéuticas con los profesionales sanitarios y con las organizaciones sanitarias; así como de interrelación entre las compañías farmacéuticas y las organizaciones de pacientes (44).

Cuando hablamos de publicidad, de publicidad interactiva, la autorregulación es una pieza clave. En nuestro país se erige en modelo la asociación Autocontrol, con un sistema gratuito de reclamaciones a resolver por un jurado integrado de expertos independientes (45). Uno de los elementos clave de un sistema de autocontrol es el sello de confianza, un símbolo del que se deriva la confianza y seguridad para los consumidores hacia la empresa adherida al sistema. En 2005 el Gobierno aprobó el distintivo público de confianza en línea a los efectos de identificar a los prestadores de servicio a través de Internet que hubieran asumido en su actuación un código de conducta determinado (46).

\section{Consideraciones finales: entre los riesgos y los beneficios de la publicidad directa al público de los medicamentos con receta, una posición favorable a la misma, pero condicionada al cumplimiento de requisitos legales}

\section{Balanza beneficios-riesgos}

Lo expuesto hasta ahora, nos permite establecer una síntesis de cuáles son los riesgos y cuáles los beneficios de la publicidad directa al público de los medicamentos con receta.

Los beneficios giran en torno a la satisfacción del derecho a la información de los pacientes o potenciales pacientes; a conocer a través de la

(44) Véase El Código de Buenas Prácticas de la Industria Farmacéuticas en www.codigofarmaindustria. org.

(45) www.autocontrol.es. Véase D. LÓPEZ JIMÉNEZ (2012), «El jurado de Autocontrol en materia de publicidad interactiva: pronunciamientos frente a terceros ajenos al sistema», Revista Aranzadi de Derecho y Nuevas Tecnologías, 30.

(46) Este distintivo fue aprobado por el Real Decreto 1163/2005 de 30 de septiembre y modificado por la disposición final tercera del Real Decreto 231/2008 de 15 de febrero.

Así véase PUERTO MENDOZA, ..., op. cit., págs. 338 y ss.: de modo general se refiere a la autorregulación publicitaria y confianza on line y señala los elementos necesarios en un sistema de autocontrol: el código de conducta, el sello de confianza y el órgano de control. 
publicidad la existencia de nuevos fármacos, de cómo funcionan y para qué deben ser utilizados; la disposición de esta información facilita su relación con el médico e, incluso, permite que el médico esté pendiente del desarrollo de los nuevos medicamentos. Los pacientes están más y mejor informados y comprenden mejor la enfermedad que padecen, se reduce la incertidumbre y se involucran más en la atención de la salud. Los pacientes bien informados pueden cumplir de modo más adecuado con el tratamiento. Otro de los beneficios es la educación en el cuidado de la salud; permite que los pacientes puedan detectar si padecen alguno de los síntomas para los que un medicamento está indicado y acudir al médico, lo que en muchos casos, podría favorecer el tratamiento temprano de una determinada enfermedad. Esta educación es especialmente positiva en un ámbito con un nivel socio-económico bajo, donde no existe una práctica habitual de buscar atención médica. La publicidad directa al público de los medicamentos con receta puede también socializar determinadas afecciones o enfermedades que, lejos de ser raras, son comunes, pero la alusión a las mismas genera cierta alerta e incluso vergüenza, como puede ser la depresión.

Los riesgos, sobre todo, se asocian con la desinformación, a pesar de la información. Esto es, la no presentación del producto enfocado a la información, sino más pendiente de la persuasión a la venta del mismo, puede provocar todo lo contrario y tener un resultado engañoso, lo que puede repercutir negativamente en la relación médico-paciente. Por otra parte, debemos tener presente también el poder de difusión de la información a través de Internet, en sus diversos formatos, especialmente, a través de las redes sociales. Aunque, si bien es cierto, precisamente por este motivo la publicidad directa al público de los medicamentos con receta puede mostrar la información veraz acerca del mismo y convertirse en herramienta útil al servicio de este derecho.

Otro de los riesgos es el posible aumento del uso/abuso de los servicios sanitarios de pacientes sin enfermedad aparente, pero que como consecuencia de los síntomas descritos en la publicidad deciden acudir al médico, con el consiguiente coste que esto implica, además de anular el valor educativo, teniendo los médicos la función de informar adecuadamente al paciente sobre el medicamento y las opciones de tratamiento, en su caso.

En Estados Unidos son muchos los estudios que se han realizado sobre el impacto de la publicidad directa al público de los medicamentos con receta, de los que se derivan como resultado tanto impactos positivos como negativos. La regulación en Estados Unidos prima ante todo la libertad de expresión, y los poderes de la FDA en este ámbito concreto son más limitados. Ello no obsta a los esfuerzos derivados de la preocupación que existe en la protección del derecho a la salud, encaminados a 
exigir que las empresas cumplan con los requisitos de exponer el justo equilibrio de los beneficios y riesgos, así como de los efectos secundarios de un medicamento, siendo revelador el alto grado de incumplimiento. Ello se agrava por la existencia de conflictos de intereses entre industria farmacéutica y médicos, así como por la presión a la que en la práctica éstos puedan verse sometidos a la hora de dispensar un determinado medicamento, exigido por el paciente, motivado por la publicidad (aunque bien es cierto que el médico tienen la última palabra). Como dato de interés en estos esfuerzos, la FDA ha creado un sitio web en colaboración con EthicAd, en el que se da información para la educación de los consumidores sobre la publicidad de los medicamentos con receta (www.fda. gov: prescription drug advertising).

En nuestro entorno, los esfuerzos encaminados a la autorregulación son muy importantes por parte de Farmaindustria y la aprobación del Código de Buenas Prácticas; además del papel otorgado y asumido, a los médicos y farmacéuticos a este respecto, como engranajes de un entramado normativo que pretende tutelar la salud pública y un uso racional del medicamento. En lo que respecta a la publicidad a través de Internet, también es necesario un mayor esfuerzo en la autorregulación y también en la corregulación, en el diseño de una Guía, en la que se determine la forma en la que debe presentarse el equilibrio justo entre los riesgos y beneficios del producto, según cuál sea el formato empleado.

\section{El equilibrio de derechos: derecho a la salud-libertad de expresión- libertad de empresa}

En el ámbito sanitario se contempla la publicidad de los medicamentos con el objetivo principal de informar al consumidor sobre el medicamento y los tratamientos destinados a mejorar la salud, al tiempo que permite a la empresa aumentar la demanda y obtener beneficios a través de la publicidad de sus productos.

Los bienes jurídicos en conflicto son dos: de un lado el derecho a la salud, que, si bien, reconocido en el artículo $43 \mathrm{CE}$, es considerado un derecho fundamental de carácter prestacional. De otro lado, la actividad publicitaria, amparada por el derecho a la libertad de expresión, del artículo $20 \mathrm{CE}$, conforme a lo establecido por el Tribunal Supremo; aunque, como se ha indicado en el apartado correspondiente, en mi opinión, más que libertad de expresión, la publicidad debe ubicarse en el derecho a la libertad de empresa del artículo $38 \mathrm{CE}$, pues, precisamente el elemento de la persuasión hace que se desvirtúe la naturaleza de la libertad de expresión en este supuesto, toda vez que el fin de lucro que lleva implícita la actividad puede ser contrario o no coincidente con la libertad de expre- 
sión. En todo caso, la libertad de empresa también es considerada un derecho fundamental, como se ha expuesto. Nos encontramos, pues, con dos derechos que tienen la misma naturaleza y cuando entran en conflicto deben someterse a un necesario análisis de los límites y condiciones a los que su ejercicio se ve sometido.

Por otra parte, teniendo en cuenta la regulación que tenemos sobre la publicidad de los medicamentos, que está enfocada a concebir la publicidad con el objetivo de informar al consumidor sobre el medicamento y los tratamientos destinados a mejorar su salud, la empresa podría ampararse en su derecho a la información del artículo $20 \mathrm{CE}$, y en este caso, podríamos entender que se trata de un derecho fundamental con todas sus garantías.

Mi conclusión en esta segunda consideración es que tratándose de dos derechos fundamentales, al menos, de la misma naturaleza, la prohibición absoluta de la publicidad directa al público de los medicamentos con receta, amparada en la protección del derecho a la salud, es una medida muy dura. Entre la permisión absoluta y la prohibición hay otras alternativas de intervención en esta libertad de la empresa, que tienen su apoyo en los beneficios derivados de este tipo de publicidad y que pretenden minimizar los riesgos a través de una adecuada regulación.

\section{La prohibición absoluta de la publicidad directa al público de los medicamentos con receta no se justifica}

Como conclusión final considero que debe levantarse la prohibición absoluta de la publicidad directa al público de los medicamentos con receta y permitir el ejercicio del derecho constitucional a la libertad de la empresa para publicitar sus productos, si bien, con las limitaciones necesarias en garantía del uso racional de los medicamentos.

En primer lugar, debe procurarse la efectividad del derecho a la libertad de la empresa, de un lado, así como, de otro lado, debe satisfacerse el derecho a la información de los usuarios. La regulación debe encaminarse a procurar los beneficios derivados de este tipo de publicidad y a minimizar los riesgos, toda vez que el producto que se publicita es considerado de cierta peligrosidad. De ahí, la necesidad de establecer límites a este tipo de publicidad que van más allá de lo establecido en la Ley General de Publicidad, sobre todo, teniendo en cuenta los riesgos que conlleva.

Si la publicidad cumple con los requisitos legales impuestos, el riesgo de no percibir una adecuada información es menor. En cualquier caso, la publicidad debe mostrar de forma clara y comprensible cuáles son los beneficios, pero sobre todo, cuáles son los riesgos y efectos secundarios 
asociados al uso del medicamento. Según el medio empleado para la publicidad, esta información ha de ser fácilmente identificable y accesible. Las dificultades son mayores cuando el medio utilizado es Internet y, más allá de la regulación, la autorregulación y la cooperación internacional juegan un papel esencial. El refuerzo de los sistemas de autorregulación debe reflejarse también en el régimen sancionador específico, de manera que la adhesión por parte de una empresa a un sistema de autocontrol, y su posterior incumplimiento se contemple, en todo caso, como infracción administrativa.

Además, en el régimen específico de la publicidad de medicamentos, la sanción por publicidad ilícita, más allá de exigir el pago de una multa, debe traducirse en una devolución de los ingresos percibidos como consecuencia de la publicidad, en cantidad estimada por la Administración, en tanto en cuanto se trata de un enriquecimiento injusto. Más aún, teniendo en cuenta que tratándose de medicamentos financiados con fondos públicos, un aumento de la publicidad conlleva cierta inducción a la prescripción y es la Administración sanitaria la que debe responder al pago de lo financiado, pues entra dentro de la cartera del sistema público. Y aunque esta no debe ser, ni es, la justificación de la prohibición, sino el uso racional del medicamento, tampoco debe asumir las consecuencias derivadas de una publicidad ilícita en su totalidad, porque en estos casos, la publicidad ha llevado a un uso irracional del medicamento.

Trabajo recibido el 7 de junio de 2017

Aceptado por el Consejo de Redacción el 20 de octubre de 2017 
LABURPENA: Ikerketa honetan, jendarteari sendagaien gaineko zuzeneko publizitatea egiteak dituen arriskuen eta onuren inguruan eztabaidatu nahi da; bereziki, medikuaren agindua behar duten edo errezeta behar duten medikamentuei dagokienez. Europar Batasunak ezarri duen esparru juridikoa medikamentuen zentzuzko erabilera lortzeari begirakoa da. Horretarako, hainbat neurri hartu dira; hala nola, errezeta behar duten medikamentuen gaineko publizitatea egiteko erabateko debekua edo errezetarik behar ez duten medikamentuen gaineko publizitate-jarduerari zenbait baldintza eskatzea. Egun, bi herrialdek bakarrik baimentzen dute beren zuzenbidean publizitate mota hori egitea: Estatu Batuek eta Zeelanda Berriak. Artikulu honetan, Estatu Batuetako eredu juridikoaren berri emango dugu, bai eta publizitate-jarduera horren arriskuei eta onurei buruzko doktrina-eztabaidaren eta botere publikoek horren gainean duten kezkaren berri eman ere. Artikulu honetan, bi kontu jartzen dira mahai gainean: babesa merezi duten bi ondasun juridikoren arteko gatazka eta zein den edo izan behar den horien babes-maila. Batetik, publizitatea egiteko eskubidea eta eskubide hori adierazpen-askatasunerako oinarrizko eskubidetzat edo enpresa-askatasunerako eskubidetzat hartzea dago, eta, bestetik, osasun-eskubide izendatutakoaren babesa dago, edota norainokoa den estatuaren erantzukizuna sendagaien zentzuzko erabileran justifikatuta jarduera pribatuan esku hartzeari dagokionez. Gainera, publizitatearen erabiltzaileek informazioa edukitzeko duten eskubidearen funtsezko balorazioa aipatzen da, bai eta jarduera horrek iragartzen den medikamentuaren onuren eta arriskuen arteko bidezko oreka izan dezala eskatzeari buruzko balorazioa ere.

GAKO HITZAK: Sendagaiak. Publizitatea. Adierazpen-askatasuna. Enpresa-askatasuna. Osasun-eskubidea.

RESUMEN: En este estudio se pretende discutir sobre los riesgos y beneficios de hacer una publicidad directa al público de los medicamentos, en especial de los medicamentos que requieren una prescripción médica o medicamentos con receta. El marco jurídico establecido desde la Unión Europea, gira en torno a la consecución de un uso racional de los medicamentos, para lo que se adoptan una serie de medidas como la prohibición absoluta de realizar publicidad de los medicamentos con receta, así como exigir ciertas condiciones a la actividad publicitaria cuyo objeto sea un medicamento sin receta. En la actualidad solo dos países permiten en su Derecho realizar esta publicidad, los Estados Unidos de América y Nueva Zelanda; damos cuenta en esta artículo del modelo jurídico estadounidense, así como del debate doctrinal y la preocupación del poder público sobre los riesgos y beneficios de esta actividad publicitaria. En este artículo se pone sobre la mesa de debate el conflicto entre dos bienes jurídicos dignos de protección, y cuál es o debe ser su nivel de protección: por una parte, el derecho a realizar publicidad y su consideración como derecho fundamental a la libertad de expresión o bien como derecho a la libertad de empresa; por otra parte, la protección del denominado derecho a la salud; y hasta dónde alcanza la responsabilidad del Estado en cuanto a su intervención en la actividad privada con la justificación en el uso racional de los medicamentos. Además, se hace referencia a la valoración sustancial del derecho a la información del usuario de la publicidad y la exigencia de que esta actividad presente un justo equilibrio entre los beneficios y riesgos del medicamento que publicita. 
PALABRAS CLAVE: Medicamentos. Publicidad. Libertad de expresión. Libertad de empresa. Derecho a la salud.

ABSTRACT: This study aims to discuss the risks and benefits of direct-toconsumer advertising of drugs and prescription drugs. The general objetive of the regulation in the European Union is to protect the rational use of drugs, and impose on Member States a ban on direct-to-consumer advertising of prescription drugs. Also, when the object of publicity is others drugs, this european regulation stablishs some conditions. Currently, only in USA and New Zealand direct-to consumer advertising of prescription drugs is allowed; we explain the American System, and expose the public debat in this subject. This article presents the conflict between two constitutional right that deserve protection: on the one hand, the right to freedom of expression, also the right to freedom of enterprise or commercial freedom; on the other hand, the so-called right to health; and what is the responsability of the State regarding its intervention in the private sector justified in rational drug use. The article also refers to the right to information and the need for advertising to show a fair balance between the benefits and risks of the advertising drug.

KEYWORDS: Drugs. Advertising. Freedom of expression. Commercial freedom. Public health. 